\title{
MORFOLOGIA E DINÂMICA FLUVIAL DO RIO NEIVA (NW DE PORTUGAL)
}

\author{
VÂNia Oliveira(1) \& M. Isabel Caetano Alves(1), (2)
}

Resumo:

Abstract:
As sociedades humanas têm ocupado as áreas ribeirinhas, verificando-se um aumento crescente ao longo da história. Por isso, o conhecimento da dinâmica fluvial às diversas escalas a que os processos operam é fundamental para o uso sustentável nestas áreas territoriais.

Em termos de configuração morfológica a bacia hidrográfica do rio Neiva é alongada. O Neiva e os seus afluentes formam um padrão de drenagem do tipo retangular com alguns troços do tipo paralelo, influenciada, em termos gerais, pela litologia local e pela direção das fraturas.

Ao longo do perfil longitudinal o rio Neiva apresenta diversos tipos de canal, verificando-se a repetição de alguns tipos a partir de Panque, o que coincide com uma rotura de declive importante no perfil longitudinal. O mais frequente é o canal ter leito de cascalho (seixos pequenos e grandes). Na área de cabeceira os controlos dominantes na ação da corrente são o declive do canal e a litologia onde este é modelado. Aí, os blocos no canal possuem sempre alguma matriz com dimensão de seixo e areão. Verifica-se que a percentagem da fração de dimensão areia tende a aumentar para jusante.

No estudo da tipologia dos canais usaram-se duas classificações diferentes. Aplicando a proposta por Montgomery \& Buffington (1997), no rio Neiva identificam-se canais do tipo A, B, C, D e E. O canal do tipo A (cascade) encontra-se na área próxima da nascente, onde o fluxo é canalizado e corre num canal único mas íngreme e também na zona das Azenhas do Neiva, em regime de fluxo baixo. Em Porrinhoso o canal é do tipo A/B (cascade e step-pool), em Godinhaços e Panque é do tipo B (step-pool). O canal do tipo C (plane-bed) encontra-se em Duas Igrejas e do tipo D (pool-riffle) nos troços de Arcozelo, de Vilar das Almas e de Tregosa. Em Cossourado a classificação atribuída foi do tipo C/D e na zona de Balugães do tipo D/C. Na zona da foz foi classificado como D/E, visto que o leito é arenoso com megaripples e ripples, típicos dos canais do tipo $\mathrm{E}$ (dune-ripple), mas, o declive apresentado é frequente nos canais do tipo D assim como as formas não atingem a dimensão de dunas fluviais.

A classificação de Rosgen $(1994,1996)$ não é aplicável ao rio Neiva. Há alguma concordância entre o tipo de canal identificado, segundo os critérios de Rosgen, para a zona da nascente (tipo A) e para as localidades de Porrinhoso e Godinhaços $\left(\mathrm{A} / \mathrm{Aa}^{+}\right)$, com as observações de campo e com os resultados obtidos segundo a classificação de Montgomery \& Buffington. Nos outros setores, os valores de entrincheiramento não são consistentes com os restantes critérios. Ainda foi possível obter combinações entre a sinuosidade, largura/profundidade e declive, exceto para os troços observados em Duas Igrejas, Tregosa e Castelo de Neiva.

A diversidade morfológica observada no rio Neiva tem valor importante para suporte da biodiversidade, já que, a estrutura dos habitats está intimamente dependente da morfologia e caraterísticas do local, no que diz respeito, por exemplo, à natureza do substrato - rochoso e aluvião.

O tipo de estudo apresentado permite compreender a dinâmica do canal à escala espaço-tempo e interpretar os indicadores de estabilidade/instabilidade do canal, de evolução, num curto espaço de tempo. Trata-se de uma abordagem integrada do sistema fluvial, a qual é um suporte para o ordenamento territorial das áreas ribeirinhas, especialmente quando aplicado à gestão ambiental destas.

Palavras-chave: Rio Neiva; Canais naturais; Caracterização geomorfológica; Sedimentologia fluvial.

Morphology and fluvial dynamic of the Neiva River (Nw of Portugal)

Human societies have occupied riverine areas, and the tendency is increasing throughout history. Therefore, the knowledge of fluvial dynamics and of the process, which operate at different scales, is fundamental to the correct planning of the sustainable use of those land areas.

The Neiva River basin is elongated. The Neiva and its tributaries form a drainage pattern of the rectangular type with some sections of the parallel type, influenced, in general terms, by the local lithology and the direction of fractures.

Along the longitudinal profile, the Neiva River presents various types of channels, occurring the repetition of certain types after Panque, coinciding with an abrupt change in the longitudinal profile slope. The most common is the channel bed of gravel (small and large pebbles). In the catchment area the controls of the stream are the channel slope and the lithology where it is modeled. There are always some blocks in the channel, with matrix of pebbles and gravels. It is increasing the percentage of the sand sediments in the

(1) Investigadora do Centro de Geologia da Universidade do Porto (CGUP / UM) e do Centro de Ciências da Terra da Universidade do Minho (CCT / UM). vania.m.g.oliveira@gmail.com

(2) Departamento de Ciências da Terra, Universidade do Minho, Campus de Gualtar, 4710-057 Braga. icaetano@dct.uminho.pt 
channel bed towards downstream. In the study of the typology of the channels were used two different classifications. Applying the criteria of Montgomery \& Buffington (1997), in the Neiva River were identified the channels types A, B, C, D and E. The type A (cascade) has in the area near the source, where the stream flows in a single steep channel, and also in the area of the Azenhas do Neiva, under low regime. The others are in: Porrinhoso, the channel is of type A/B (cascade and step-pool); Godinhaços and Panque, of type B (step-pool); Duas Igrejas, the C-type channel (plane-bed); type D (pool-riffle) in the areas of Arcozelo, Vilar das Almas and Tregosa; Cossourado, type C/D, and Balugães area, of type $\mathrm{D} / \mathrm{C}$; in the mouth area, channel was evaluated as $\mathrm{D} / \mathrm{E}$, because the sand bed have megaripples and ripples typical of channel type E (dune-ripple), but the slope type is frequent in D-channels, and landforms do not reach the dimension of river dunes.

It was found some correlation between the type of channel identified, according to the classification criteria of Rosgen (1994, 1996), for the source area (type A), and for Porrinhoso and Godinhaços (A/ $\left./ \mathrm{Aa}^{+}\right)$. There was observed reliability with the field observations and results obtained by the classification of Montgomery \& Buffington. In other sectors, the values of entrenchment are not consistent with the other criteria. It was possible to get combinations of the sinuosity, width / depth and slope, except for the sections observed in Duas Igrejas, Tregosa, and Castelo de Neiva.

The morphological diversity observed in the Neiva River has important value to support biodiversity, since the structure of habitats is closely dependent on the morphology and characteristics of the place, as regards, for example, the nature of the substrate - rock and alluvium.

The type of study presented allows to understand the dynamics of the channel, and interpret the stability/ /instability of the channel, throughout the space-time. This is an overview of the river system, which is a support for the riparian areas, especially to be applied to the environmental management of these.

Key-words: Neiva River; Natural channels; Geomorphic characterization; Fluvial sedimentology.

\section{INTRODUÇão}

O Homem retira do ambiente natural todos os recursos necessários à sua sobrevivência. Os rios são parte desses recursos essenciais, cuja importância é irrefutável para o quotidiano das populações humanas. Elas têm ao longo dos tempos ocupado preferencialmente áreas de vale, sendo constatável que esta tendência, crescente na atualidade, é observável em sentido lato, por todo o mundo incluindo em Portugal. A edificação de estruturas de cariz permanente em áreas de fundo do vale é passível, por si só, de ser uma ocupação de risco. A esta, adicionam-se todos os restantes usos das vertentes, cujos efeitos são dinamicamente equilibrados a montante e a jusante desses locais. Além da importância do ordenamento territorial nestes setores, assiste lembrar que a gestão das correntes fluviais per se nem sempre segue a opção mais acertada e, em grande parte dos casos, os referidos assuntos são tratados por serviços distintos da administração pública. Estes temas de importância social são encarados pelo cidadão comum com distanciamento, sendo o comportamento de indiferença da população residente naquelas regiões quebrado apenas em situações de crise declarada ou eminente. Referimo-nos a: riscos de inundação e falta / racionamento / má qualidade da água das correntes fluviais. Urge pois aumentar a literacia do público a todos os níveis, contribuindo para que as populações atuais e futuras tomem consciência do valor do ambiente fluvial e da necessidade do seu uso de modo sustentado. Neste sentido, apresenta-se este estudo sobre a morfologia do rio Neiva e sua relação com os processos de dinâmica fluvial, numa análise da bacia do rio em especial ao longo do seu perfil longitudinal.

\section{Metodologia de Trabalho}

Para o conhecimento das caraterísticas morfológicas e das particularidades geológicas do rio Neiva este estudo foi desenvolvido recorrendo às seguintes metodologias de trabalho de campo: seleção dos setores tipo e amostragem do leito e das barras do canal fluvial.

Na descrição morfológica dos tipos de canais optou-se pelas classificações de Rosgen (1994, 1996) e de Montgomery \& Buffington (1997). A descrição geológica da bacia do rio Neiva teve por base a cartografia e trabalhos de Pereira (1989, 1992), Alves (1995, 1999), Oliveira (2007) e Alves \& Oliveira (2008).

\section{ENQUAdRAMENTo do Rio NEIVA}

$\mathrm{O}$ rio Neiva faz parte do conjunto dos rios que drenam a região a norte do Porto genericamente conhecida por Minho ocidental. O relevo é caraterizado pela existência duma compartimentação topográfica, em blocos de altitude crescente para este e em depressões alinhadas com orientação geral ENE-WSW, os vales resultantes da morfogénese fluvial (Fig. 1).

$\mathrm{O}$ rio Neiva nasce no Monte Oural. Ao longo do seu percurso, com aproximadamente $40 \mathrm{~km}$ de com- 


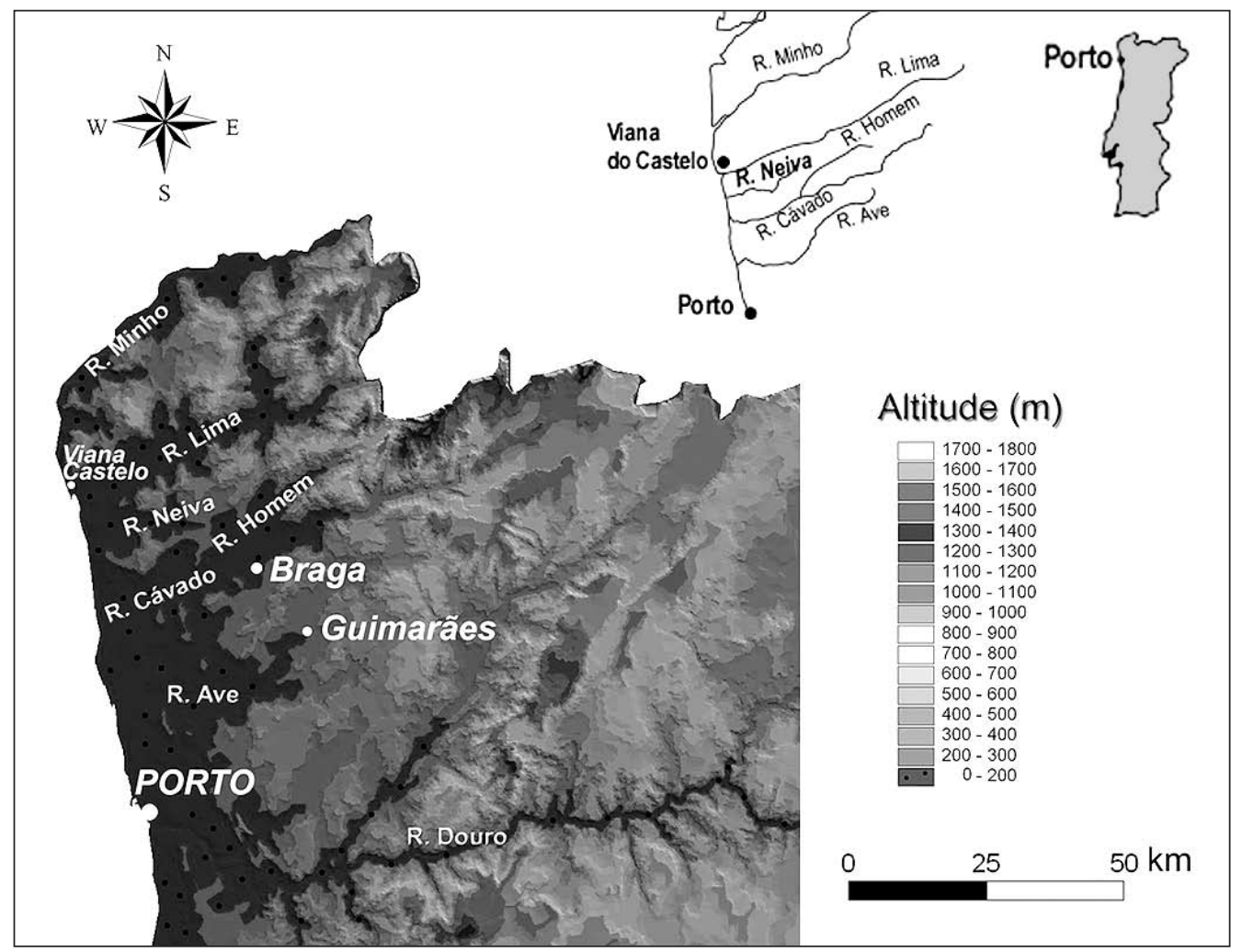

Fig. 1. Localização da bacia hidrográfica do rio Neiva no NW de Portugal e num extrato do mapa de altimetria do Continente, adaptado do Atlas do Ambiente Digital, 1/1.000.000 (Instituto do Ambiente, 2003).

Fig. 1. Location of the Neiva River basin in NW of Portugal, and in the Altimetry Continent map, extract adapted from the Digital Environment Atlas 1/1,000,000 (Instituto do Ambiente, 2003).

primento, atravessa cinco áreas administrativas (Vila Verde, Ponte de Lima, Barcelos, Viana do Castelo e Esposende), desaguando diretamente no oceano Atlântico, em Castelo do Neiva. Trata-se de uma bacia hidrográfica, exorreica, limitada a norte, pela bacia hidrográfica do rio Lima, e a sul pela bacia do Rio Cávado (sistema fluvial Cávado-Homem).

Na região dominam as rochas graníticas, hercínicas, que intruem rochas paleozóicas, do Câmbrico e principalmente do Silúrico, ocorrendo ainda rochas pliocénicas, plistocénicas e holocénicas, presentes em depósitos de terraços fluviais e de terraços marinhos, nas praias e nos depósitos dunares (PEREIRA 1989, 1992; M.I.C. Alves 1995, 1999; A.M.C. ALVES 1996).

\section{Descrição do Padrão de Drenagem e do Percurso LONGITUdiNAL DO RIO NEIVA}

A bacia de drenagem é a área geográfica que abrange todos os locais onde a água que aí precipita é drenada para o mesmo curso de água, cujo limite com outras áreas adjacentes constituem linhas imaginárias conhecidas por divisórias (Fig. 2), traçadas sobre os pontos de maior altitude do relevo interbacias (SCHUMm 2005; RosGen 1994, 1996; DingMAN 2009). No caso da bacia do rio Neiva o ponto de maior altitude situa-se na sua nascente, o Monte Oural (+722 m), sendo o de S. Miguel (+500 m), ainda na cabeceira, e os restantes, listando de montante para jusante, os seguintes: fazendo divisória com a bacia do rio Lima, bacia a norte, Barcas (+602 m), Nora (+573 m), Geraz (+484 m), Cruzeiro (+477 m), Roques (+275 m) e S. Romão (+186 m), fazendo divisória com a bacia do rio Lima, a norte; Borrelho (+496 m), Moinho Velho (+460 m), Fonte Grande (+380 m), S. Gonçalo (+488 m) e Maceira (+284 m), do lado este e sul. Trata-se de uma pequena bacia hidrográfica, com $241 \mathrm{~km}^{2}$ de área, cujos relevos mais elevados, exceto na nascente do rio, atingem entre $+400 \mathrm{~m} \mathrm{a}+500 \mathrm{~m}$ em cerca de dois terços, na área da bacia.

Em termos de configuração morfológica a bacia hidrográfica do rio Neiva é alongada (Fig. 3), observando-se uma dissimetria quanto ao comprimento e ao grau de hierarquia dos afluentes nas duas mar- 


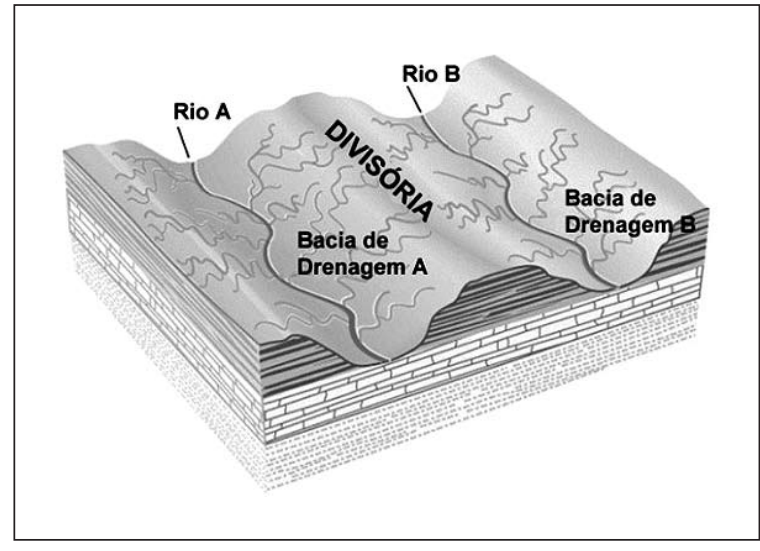

Fig. 2. Desenho esquemático, adaptado de Press \& Siever (2001), representando um setor de duas bacias de drenagem e o relevo que as separa (divisória).

Fig. 2. Drainage basins and the relief separating them. Figure adapted from Press \& Siever (2001).

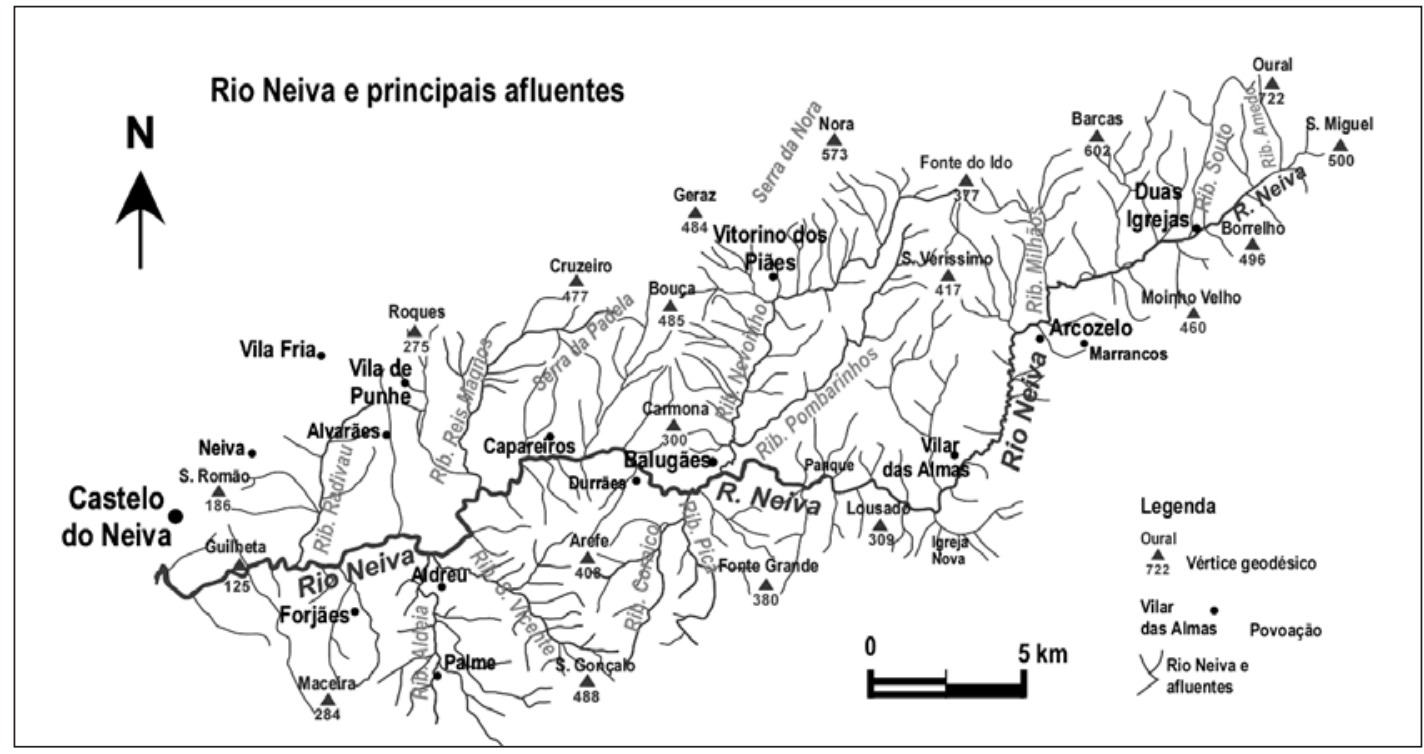

Fig. 3. Rede de drenagem da bacia do rio Neiva, com indicação dos principais afluentes. Desenho esquemático realizado sobre as Cartas Corográficas à escala 1/50 000, folhas 5-A, 5-B e 5-C da Série 7810, Edição 2, IGCP.

Fig. 3. Drainage network of the Neiva River basin with the main tributaries. Drawing, done on scale 1/50 000 maps (Cartas Corográficas, folhas 5-A, 5-B e 5-C, Série 7810, Ed. 2, IGCP).

gens. Não se trata duma bacia alongada em sentido restrito, tal como a da figura 4.a, pois neste tipo os afluentes desaguam diretamente no rio principal e ao longo do percurso deste. Nem tão pouco a drenagem está hierarquizada como é exemplificado na figura 4.b. Os afluentes da margem direita do rio Neiva têm maior comprimento e o número de confluências é superior ao da outra margem. No conjunto, o Neiva e os afluentes formam um padrão de drenagem do tipo retangular com alguns troços do tipo paralelo (Figs. 3 e 5). A rede de drenagem é influenciada pela litologia local e pela direção das fraturas, em termos gerais.

Segundo Schumm (2005) podem identificar-se três zonas morfológicas principais num sistema fluvial: a área fonte (Zona 1); a de transferência (Zona 2) e a de deposição (Zona 3). A Zona 1 corresponde à área geográfica coletora de água e fonte de sedimentos (Fig. 6). Esta é uma zona sobretudo dominada por processos de erosão da qual resulta a produção de sedimentos. Na Zona 2, verificam-se dominantemente os processos de transferência, onde, e supondo um canal estável, a chegada de sedimentos (input) pode igualar a erosão (output). É certo que a mobilidade dos sedimentos está dependente das condições hidrológicas da bacia, portanto, em situações de maior disponibilidade de água, o caudal aumenta e com ele a transferência dos sedimentos que ocuparão posições mais a jusante das iniciais. A Zona 3 refere-se à área de deposição de sedimentos, o que conduz a um aumento do volume de material acumulado nestas (Fig. 6). 


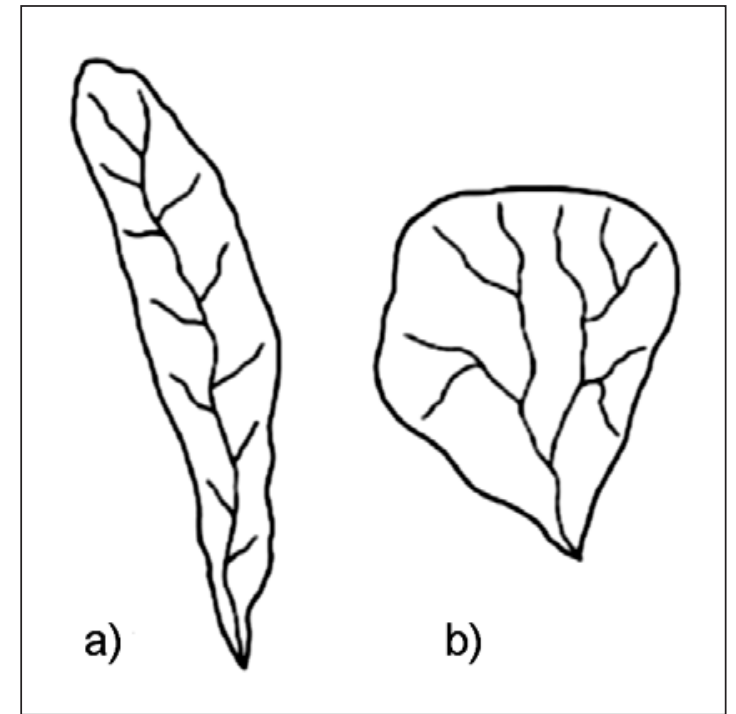

Fig. 4. Geometria de duas bacias de drenagem. Adaptado de Schumm (2005).

Fig. 4. Geometry of two drainage basins. Figure adapted from Schumm (2005).

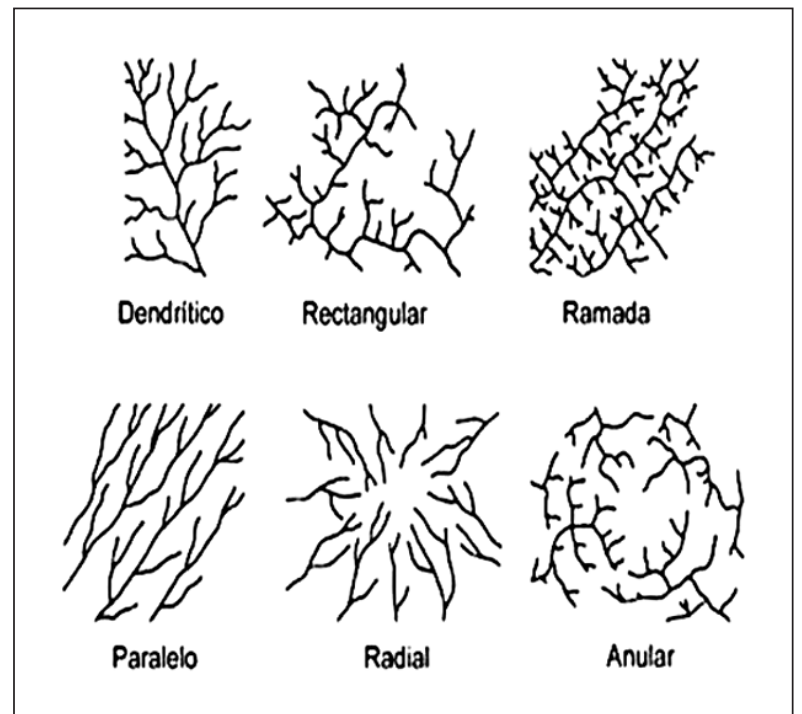

Fig. 5. Tipos de padrão de drenagem, exemplos. Adaptado de Bloom (1999).

Fig. 5. Drainage pattern types, examples. Figure adapted from Bloom (1999).

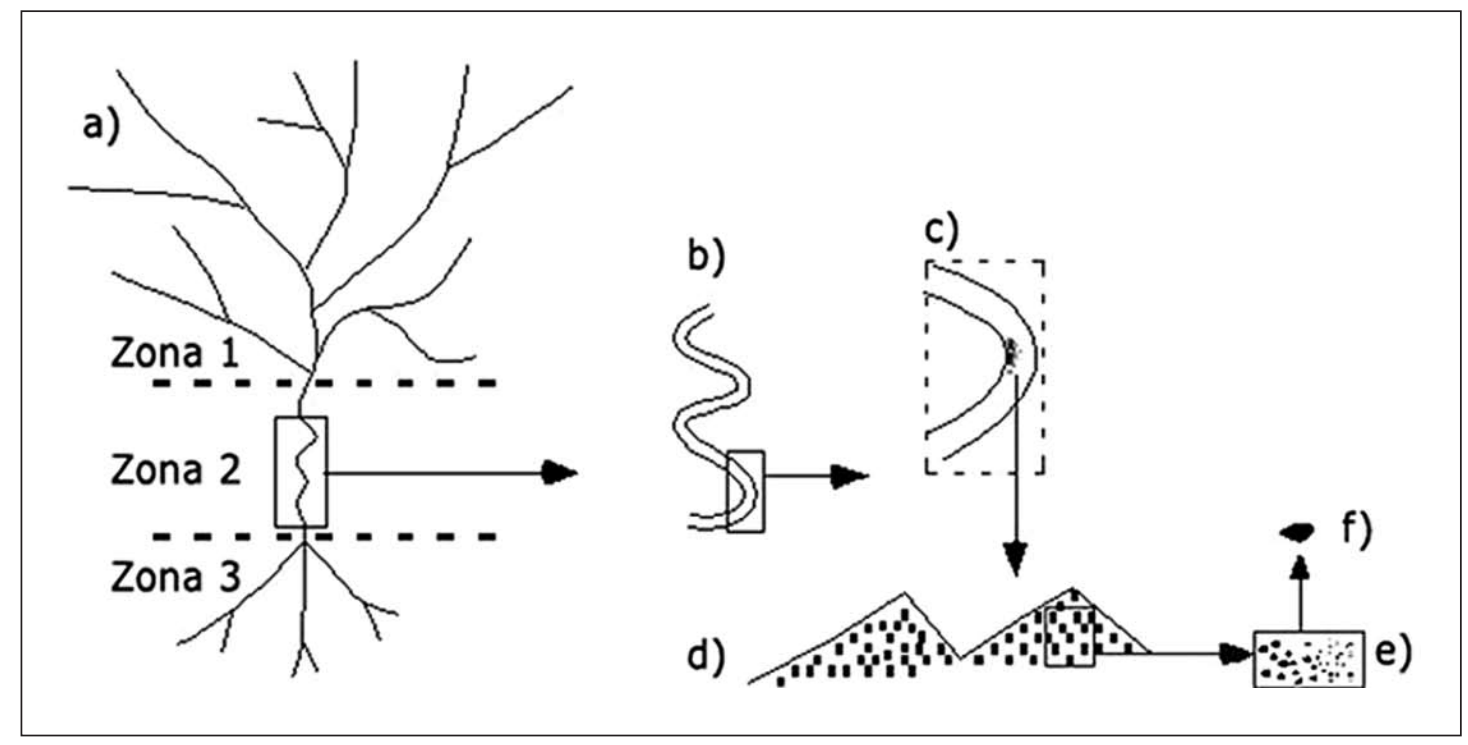

Fig. 6. Zonas componentes do sistema fluvial segundo Schumm (1977, citado em SCHUMM 2005).

Fig. 6. Areas of the fluvial system (SснUмm 1977, quoted in SснUмm 2005).

$\mathrm{O}$ zonamento, descrito anteriormente, corresponde a uma análise à escala da bacia, dependendo da sua morfologia, da densidade e organização dos afluentes, isto é, do padrão da rede de drenagem (compare-se as figuras 4, 5 e 6a). Na realidade, os sedimentos são armazenados, erodidos e transportados nas três zonas, dependendo da escala de análise. Contudo, pode identificar-se em cada uma delas, um dos processos referidos, como dominante (Figs. $6 \mathrm{a}$ à $6 \mathrm{e}$ ). Na situação de maior disponibilidade de água o caudal aumenta e com ele a transferência dos sedimentos para jusante da posição inicial. Nesta situação haverá reorganização das áreas de armazenamento que, em função do acréscimo do fornecimento de sedimentos, poderá provocar alterações morfológicas no canal para facilitar a transferência. $\mathrm{Na}$ Zona 3 a deposição é o processo dominante, conduzindo ao aumento no volume de sedimentos acumulados nessas áreas (Fig. 6).

Aplicando à bacia do rio Neiva, o modelo referido, as zonas de maior erosão (Zona 1) coincidem com as áreas de cabeceira, do rio Neiva e dos seus 
afluentes. O Monte Oural é um relevo divisório de três bacias hidrográficas, nomeadamente do rio Neiva, do rio Lima e do rio Homem, o maior afluente do rio Cávado. No setor da bacia do Neiva aflora o Granito de Braga e destacam-se os pântanos do Oural, áreas encharcadas com sedimentos finos, por vezes bastante coesos, onde o escoamento ainda não é do tipo canalizado (Fig. 7). Os cursos de água nesta área de cabeceira, da bacia de drenagem do rio Neiva, distribuem-se num padrão radial, a partir do Monte Oural. O ribeiro de Ameda, o ribeiro do Souto e outros mais pequenos, que coletam as águas do Monte Oural, têm as suas confluências na margem direita do rio Neiva, no troço a montante de Duas Igrejas (Fig. 5). A Zona 1, descrita no modelo de Schumm (2005), tem início um pouco mais abaixo, onde o declive aumenta e se define o escoamento canalizado, propriamente dito. O ribeiro do Souto é o afluente mais comprido do rio Neiva, situado próximo do limite com a bacia do rio Lima. Perto da nascente o leito do ribeiro do Souto tem alguns seixos e blocos, predominantemente graníticos e alguns de metassedimentos. A largura do canal e o declive variam para jusante, os sedimentos no canal tendem a ser angulosos com matriz de areia muito grosseira a grosseira. Nas zonas onde a inclinação é maior, o talvegue é uma rampa granítica concentrando-se os sedimentos no fim desta, no ponto de rotura para pendor mais suave (Fig. 8). Para jusante o canal fluvial é mais profundo, as suas margens são modeladas no granito alterado, têm vegetação (frequentemente silvas) onde se prendem pequenos ramos e outros destroços associados, transportados pela corrente em situação de caudal de cheia.

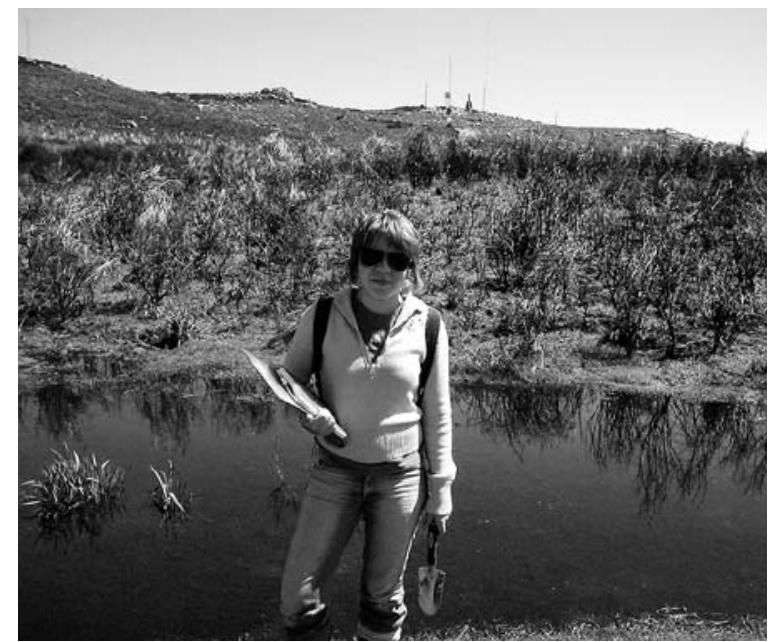

Fig. 7. Os pântanos do Oural junto à nascente do rio Neiva, no Monte Oural.

Fig. 7. Swamps near the catchment of the Neiva River on Mount Oural.
Em Porrinhoso as águas do ribeiro do Souto foram aproveitadas para movimentar moinhos, atualmente inativos. Para jusante desta povoação o ribeiro adquire um traçado mais retilíneo, com direção aproximada $\mathrm{N} 10^{\circ} \mathrm{E}$, ladeando o Monte Sabroso pelo lado oeste.

Na nascente do rio Neiva, no Monte Oural o rio tem orientação NNW, corre sobre o Granito de Braga, a rocha local, um granito de grão fino a médio, com esparsos megacristais, de duas micas, biotítico (Fig. 9). Depois de intersetar os filões de quartzo em Godinhaços o trajeto muda bruscamente para NNE. O canal passa a ser modelado no Granito da Zona de Cisalhamento Vila Nova de Cerveira-Ponte de Lima, um granito de grão médio de duas micas, pertencendo aos Maciços Alóctones. O rio Neiva junto de Godinhaços corre num canal único, modelado no granito duro, cujas margens distam em média 1,2 metros (Fig. 10a). A maioria dos sedimentos é de dimensão seixo grande, onde predominam os subangulosos acompanhados duma pequena população de outros menores mais desgastados e de alguma areia (Fig. 10b). Para jusante corre novamente sobre o Granito de Braga, atravessando o contacto com o anterior, por falha provável (PEREIRA 1989), a montante da confluência do ribeiro de Souto, próximo de Duas Igrejas. Nesta região corre num canal único, mais profundo (Fig. 11). Mantém o seu percurso NNE até à confluência do ribeiro de Milhãos, na margem direita. Neste local muda de direção para NS, seguindo, grosso modo, o carreamento de Vila Verde, que separa as rochas atribuídas ao Silúrico (Indiferenciado), nomeadamente a Unidade Minho Central e Ocidental (UMc), do Autóctone.

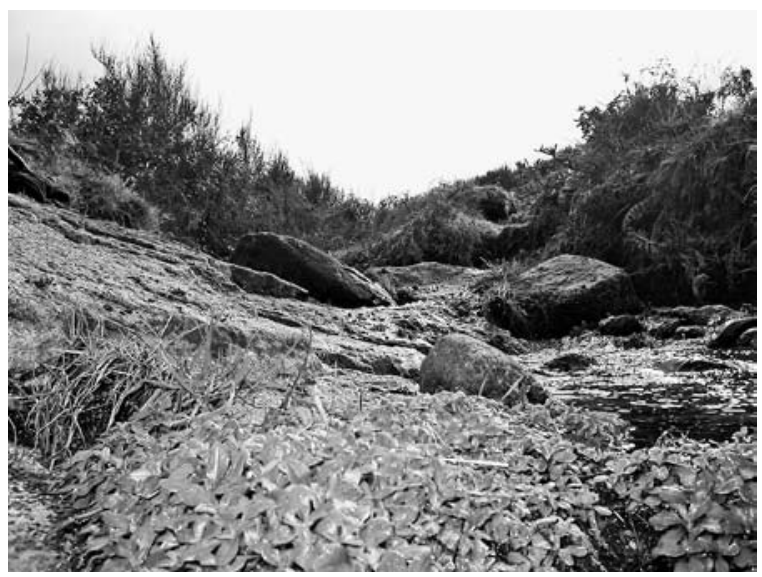

Fig. 8. Aspetos do canal do Ribeiro do Souto vendo-se o leito granítico exposto na rampa e no fim desta, uma pequena piscina com blocos, seixos e areia.

Fig. 8. Channel features of the Ribeiro do Souto. The channel bed is a granitic ramp, and has at the end a small pool, with blocks, pebbles and sand. 


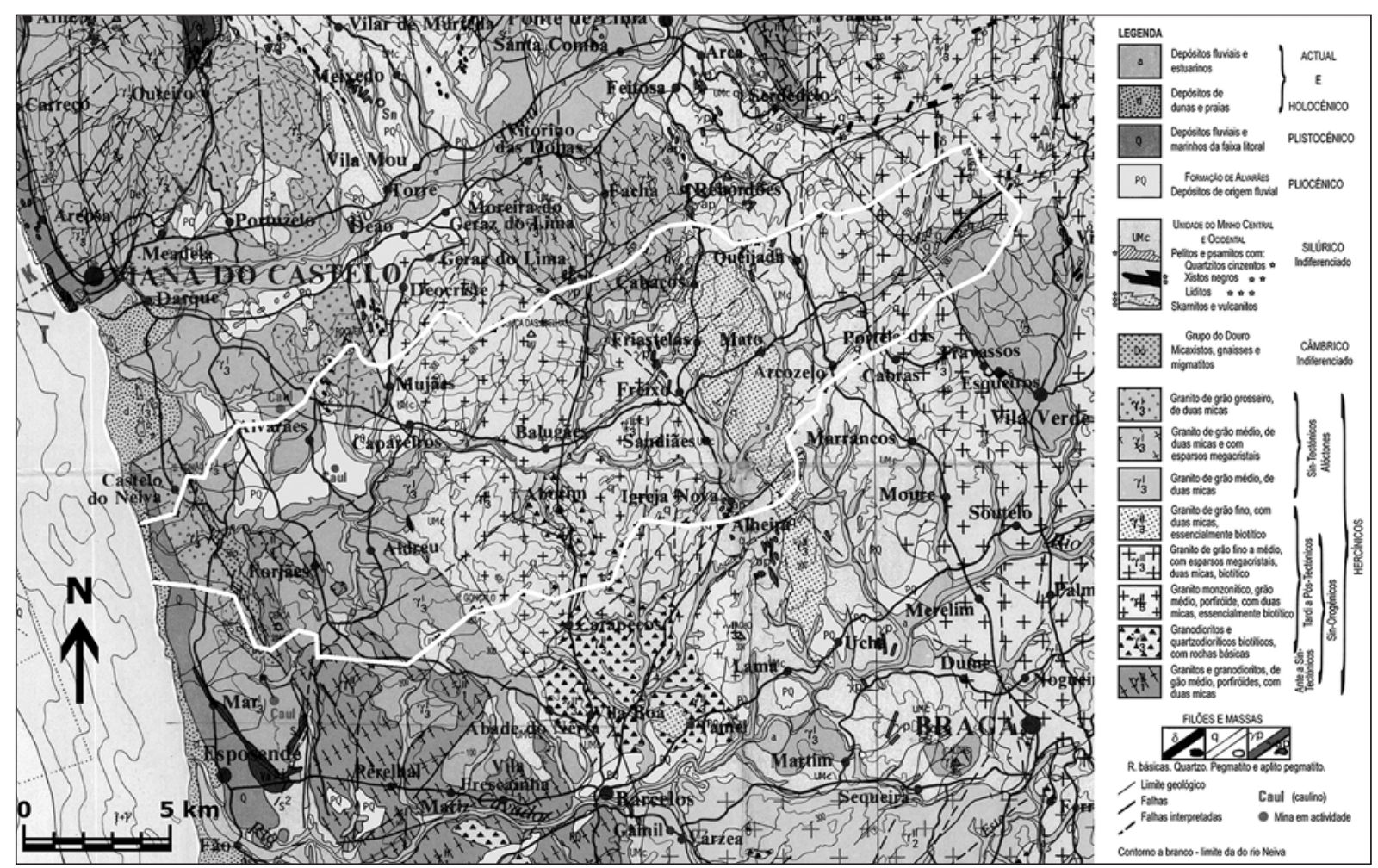

Fig. 9. Extracto da Carta Geológica de Portugal, escala 1/200 000, Folha 1 (PereIRA 1989), modificada com base em Alves (1999). Legenda adaptada à área da bacia do rio Neiva.

Fig. 9. Extract from the Geological Map of Portugal, scale 1/200 000, Folha 1 (PEREIRA 1989), modified based on Alves (1999). Legend adapted to the basin of the Neiva River.
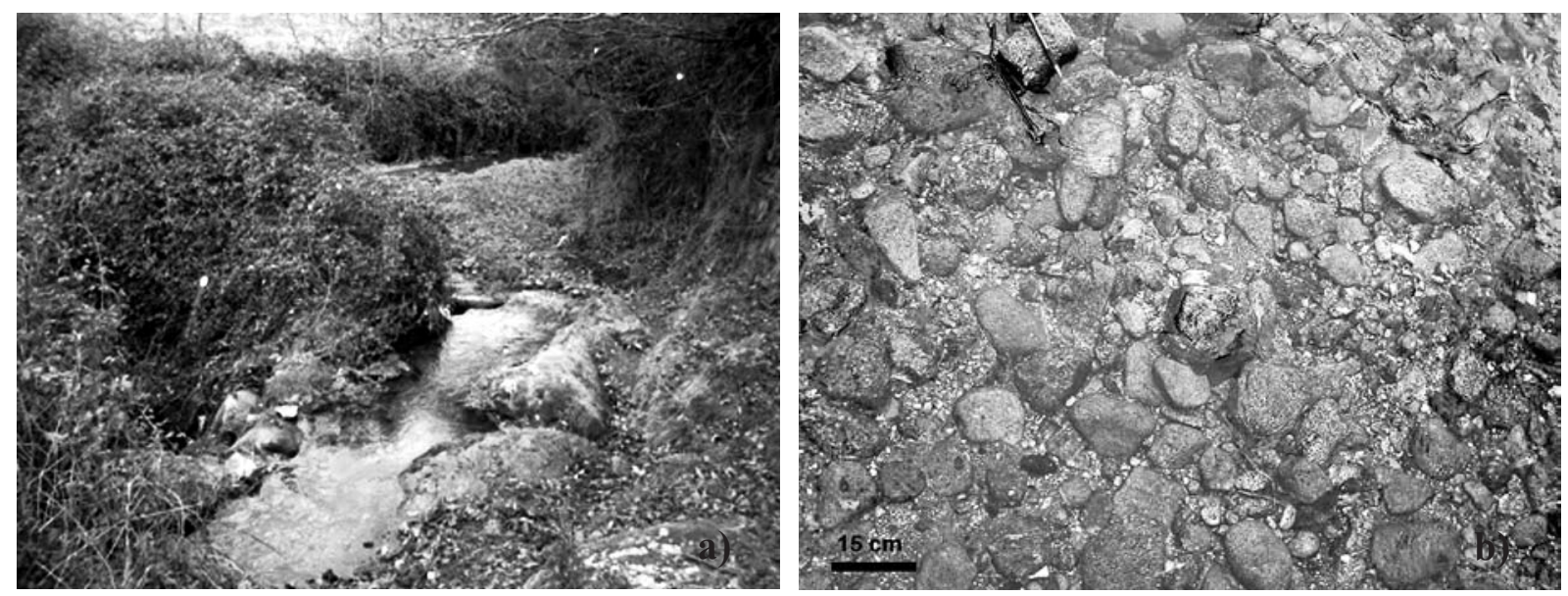

Fig. 10. Rio Neiva, na região de Godinhaços: a) canal único modelado no granito local; b) leito com sedimentos grosseiros, a maioria pouco desgastados.

Fig. 10. The Neiva River, in the region of Godinhaços: a) single channel modeled on the local granite; b) bed with coarse sediments, most with slightly rounded vertices and edges. 


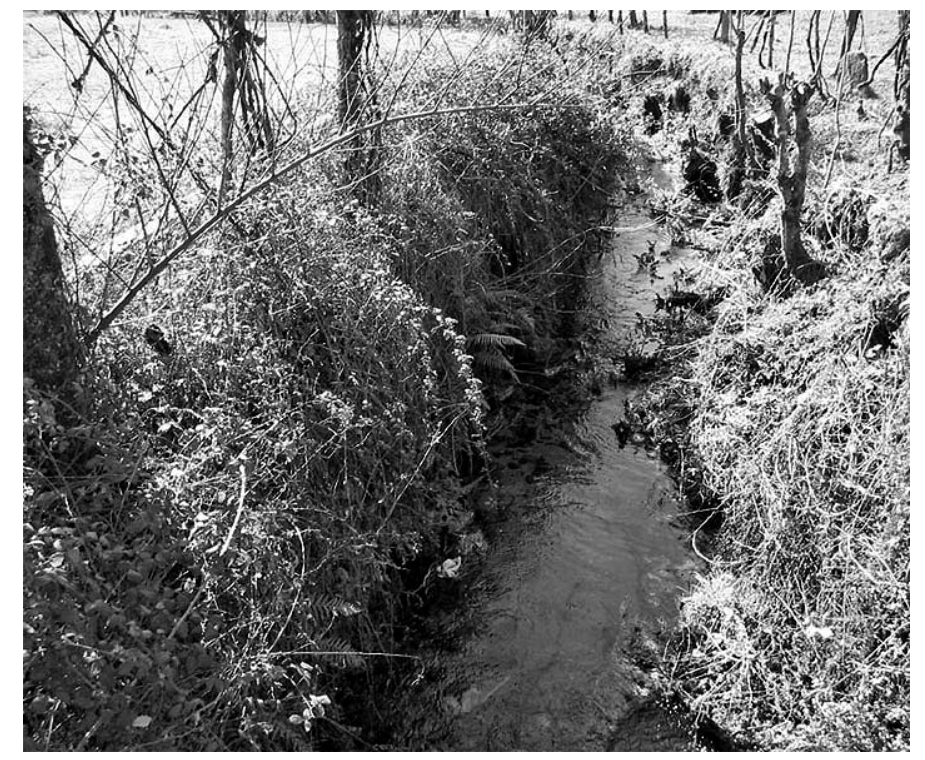

Fig. 11. O rio Neiva na região de Duas Igrejas, canal único.

Fig. 11. The Neiva River in the region of Duas Igrejas, single channel.
Salienta-se que o vale do rio Neiva é aberto e com fundo largo, alargando até Panque. Este tramo é típico da zona de transferência (Zona 2 de Schumm 2005), onde predomina o transporte dos sedimentos dependendo da energia da corrente.

$\mathrm{Na}$ zona de Arcozelo, o rio inflete num curto troço com orientação NNE, retomando novamente a orientação N-S até próximo de Vilar das Almas. Entre Arcozelo e Vilar das Almas o substrato do rio é constituído por rochas silúricas (UMc) e pelo Granito de Parada de Gatim, um granito de grão fino, de duas micas, essencialmente biotítico. $\mathrm{O}$ traçado, modelado em metassedimentos da UMc, tem configuração meandriforme até ao alvéolo de Igreja Nova.

Na região de Arcozelo, o substrato é composto por metassedimentos silúricos pertencendo à UMc (Fig. 9). O talvegue do rio Neiva tem menor declive e a relação largura/profundidade do rio é bastante maior. A distância entre as margens é de cerca de 4 metros. O leito é de aluvião. Os sedimentos são de dimensão seixo, mais pequenos que os da zona a montante, e estão contidos numa matriz arenosa. A composição dos clastos é diversificada, rochas metamórficas e graníticas, todos apresentando desgaste. As correntes circulam com velocidade e trajetórias variáveis, originando acumulações nalguns locais junto às margens mas, preferencialmente, em barras longitudinais na parte central do canal fluvial. As barras centrais mais extensas estão estabilizadas pela vegetação, como os amieiros e até as videiras (Fig. 12). O fluxo aquoso é dividido em dois circuitos principais, circundando estas barras, que não se desenvolvem em posição de perfeita simetria relativamente às margens do rio. $\mathrm{A}$ velocidade da corrente é distinta, reconhecendo-se

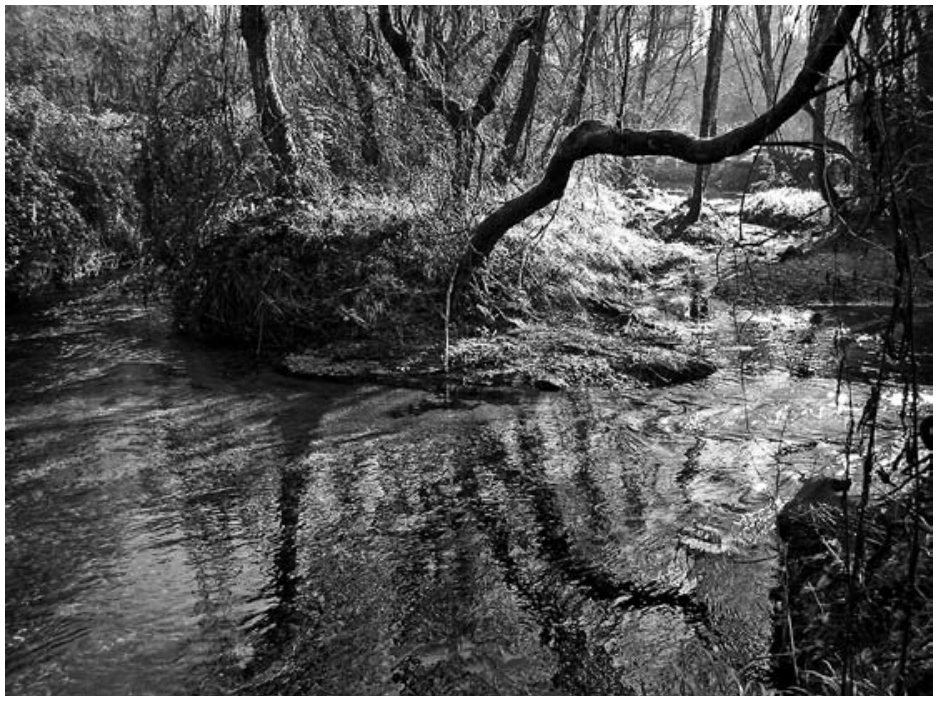

Fig. 12. O rio Neiva na região de Arcozelo, fotografia dos canais que circundam a barra central.

Fig. 12. The Neiva River in Arcozelo, photography of the channels surrounding the central bar. 
pelas caraterísticas das aluviões, maior quantidade de areia/seixos e maior desgaste no canal principal. A zona marginal da planície de inundação foi aproveitada para cultivo agrícola.

É no troço médio do percurso longitudinal que o rio Neiva possui maior largura, aumentando para cerca do dobro, ou seja, 8 metros, entre as margens do canal, próximo da localidade de Vilar das Almas (Fig. 13), para jusante de Arcozelo. Neste setor o rio corre sobre o Granito de Parada de Gatim (Fig. 9). A corrente fluvial é mais fraca, observando-se barras arenosas, por vezes com ripples na superfície, bem individualizadas dos clastos mais grosseiros no leito do canal. Esporadicamente encontram-se sedimentos lodosos em concavidades marginais, afastadas do trajeto de maior velocidade da corrente. A planície de inundação é larga e cultivada até às margens do rio.

O vale estreita e o declive do talvegue aumenta no troço de Panque. Trata-se dum setor do vale do tipo canhão, sendo o canal fluvial confinado no Granito de Coussorado, um granito monzonítico, de grão médio, porfiroide, com duas micas, essencialmente biotítico (Figs. 3 e 9). Nalguns pontos do vale os blocos ocupam toda a largura do canal, sendo o trajeto da corrente por entre os blocos. Nalguns troços o canal é do tipo step-pool (Fig. 14). Neste setor do rio a corrente tem maior velocidade devido à relação largura/profundidade do canal, refletindo-se na dimensão das aluviões. Nestes casos praticamente não se observam partículas de dimensão areia.

Para jusante da localidade de Panque, mantém-se a mesma natureza do substrato, mas o vale é mais

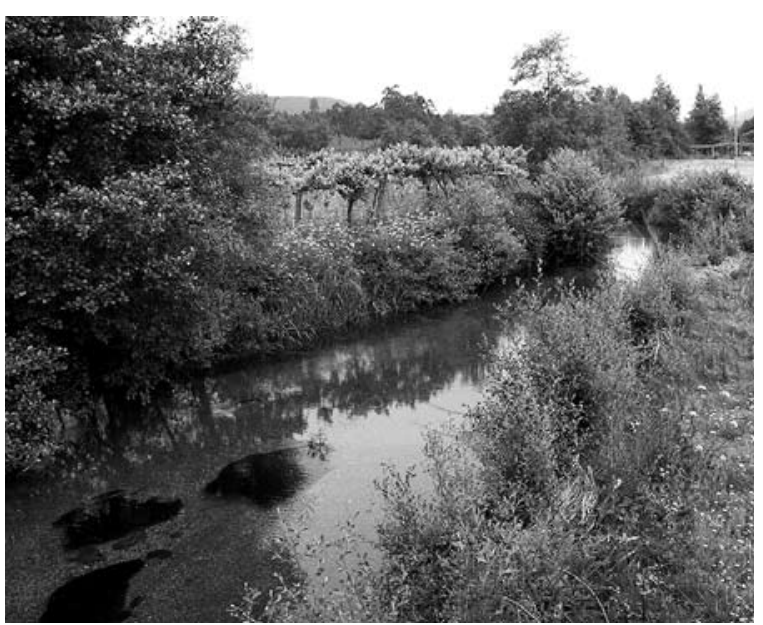

Fig. 13. O canal fluvial do rio Neiva em Vilar das Almas. Os terrenos da planície de inundação estão ocupados por atividades agrícolas. Vista para montante.

Fig. 13. The channel of the Neiva River in Vilar das Almas. The floodplain is used with agricultural activities. View to upstream. aberto, diminuem os blocos no canal e o declive do leito e aumenta a razão largura/profundidade. Há maior distância entre as margens do canal, distando elas entre si aproximadamente 12 a 13 metros. A corrente perde velocidade.

Na zona de Cossourado o canal é coberto por aluviões de dimensão seixo com matriz arenosa, essencialmente de quartzo. Por vezes, avistam-se algumas partículas maiores, subangulosas de dimensão bloco, mas menores que $40 \mathrm{~cm}$. O afastamento das margens do vale, o alargamento do canal e o menor declive do talvegue explicam o tipo de aluviões encontrados.

Para jusante o declive do talvegue tende a diminuir e com ele novamente a velocidade da corrente. $\mathrm{Na}$ localidade de Balugães o leito do canal é coberto por aluviões mais finos, havendo grande quantidade de areia. $\mathrm{O}$ fundo do canal tende a ser do tipo fundo plano. O traçado do canal é sinuoso, devido à acumulação de areia em barras laterais, de pouca altura mantendo-se emersas mesmo em regime baixo.

Observa-se na zona de Balugães, um vale novamente muito largo. Neste setor, o rio recebe as águas coletadas pelos ribeiros de Pombarinhos e de Nevoinho, ambos confluindo antes de desaguar na margem direita do rio Neiva. Na margem esquerda encontram-se o ribeiro de Cornico, afluente do ribeiro de Pica que desagua no rio Neiva (Fig. 3). Na região de Capareiros-Tregosa o rio Neiva tem um breve troço nos metassedimentos (UMc), passando o seu trajeto a ser no Granito de S. Lourenço, um granito de grão médio de duas micas. Em Tregosa é constituído por seixo e areão, a corrente fluvial circula entre as barras de areia, mais volumosas e emersas

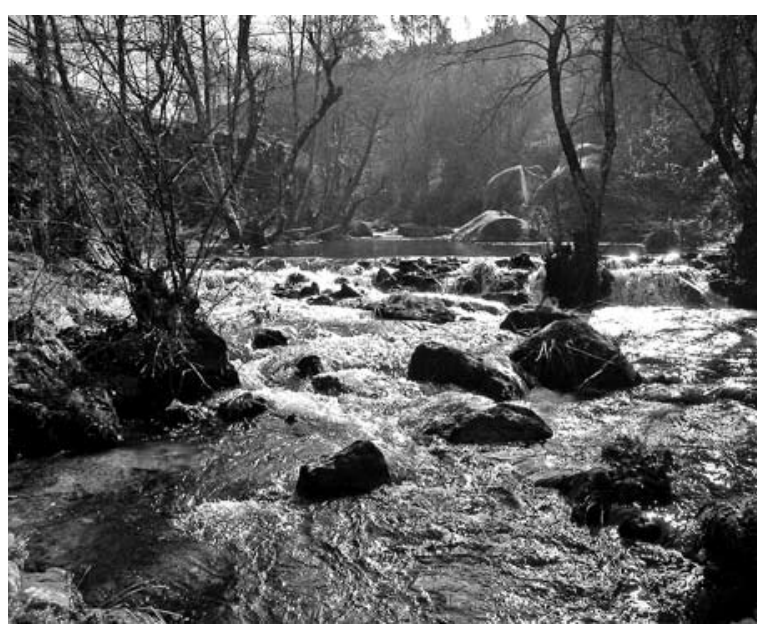

Fig. 14. O vale do rio Neiva próximo de Panque, mostrando um troço do canal do tipo step-pool, os blocos e a vegetação.

Fig. 14. The valley of the Neiva River near Panque, showing a section of the channel step-pool type, the blocks and vegetation. 
(Fig. 15) e a profundidade de água não atinge meio metro durante a época estival no canal principal. Salienta-se aqui a presença de uma grande barra longitudinal estabilizada com vegetação arbórea, de cascalho e com matriz de areia, cujos seixos apresentam desgaste superior ao observado anteriormente no rio (Fig. 16). O declive do talvegue sofre algumas variações na região surgindo pontualmente alguns rápidos, coincidentes com afloramentos do substrato granítico mais salientes no leito.

No lugar da Ponte, em Fragoso, a distância entre as margens do rio Neiva é de cerca de 25 metros. Encontra-se grande quantidade de areia granítica e os sedimentos grosseiros são pouco frequentes. $\mathrm{O}$ talvegue tem pouco declive, o canal é mais profundo e a corrente fluvial é mais lenta.

Próximo de Forjães o leito é encaixado serpenteando quer no Granito de S. Lourenço quer no Granito de Barcelinhos, até Guilheta, na zona de Castelo de Neiva. Os principais afluentes são, para jusante de Capareiros, o ribeiro dos Reis Magnos e o ribeiro de Radivau, na margem direita e na margem esquerda os ribeiros de S. Vicente e da Aldeia. Em S. Paio de Antas o fluxo aquoso circula num canal profundo, escavado em granito e em metassedimentos, com margens facilmente inundáveis, distanciadas de aproximadamente 18 metros. Veem-se raros blocos de rocha granítica de grande dimensão, acompanhados por areia. O vale do rio Neiva estreita e o declive do leito aumenta no setor de Guilheta, na zona de Castelo de Neiva. O percurso é sobre as rochas câmbricas do Grupo Douro, nomeadamente micaxistos, gnaisses e migmatitos, e sobre o Granito de Castelo do Neiva, que designa o conjunto de granitos e granodioritos de grão grosseiro de duas micas, que fazem parte da antiforma Castelo de Neiva-Esposende (PEREIRA 1989, 1992).

$\mathrm{Na}$ parte terminal o rio atravessa depósitos de praias antigas do Plistocénico e de praias e dunas do Holocénico (Alves 1996). Perto da capela de Sta. Tecla as margens do rio Neiva estão muito urbanizadas, havendo construções situadas praticamente em cima do canal, onde predomina a areia.

A zona seguinte é já próximo da foz (Fig. 17). Aí a vegetação é completamente diferente. Existem espécies caraterísticas das dunas. A corrente fluvial é fraca, quase ausente. Abundam os sedimentos arenosos. O canal fluvial tem grande largura, distando as margens cerca de 40 metros, estando muito vulneráveis às inundações. À medida que o rio Neiva se aproxima da foz os sedimentos são cada vez mais ricos na dimensão areia e os clastos são ligeiramente mais grosseiros, polidos e muito rolados.

Na bacia do rio Neiva ocorrem também filões e massas de quartzo, pegmatito e aplito-pegmatito, em toda a área. $\mathrm{Na}$ zona da nascente há filões de rocha básica. Existe outra fácies de granito, o Granito de Perre, aflorando no monte sobranceiro a Vila Franca (Viana do Castelo), que é um granito de grão grosseiro e duas micas (PEREIRA 1989, 1992). E, ainda, há ocorrência da Formação de Alvarães, que é um registo da sedimentação continental cenozóica, atribuído ao Placenciano aqui na região de Alvarães (Alves 1999).

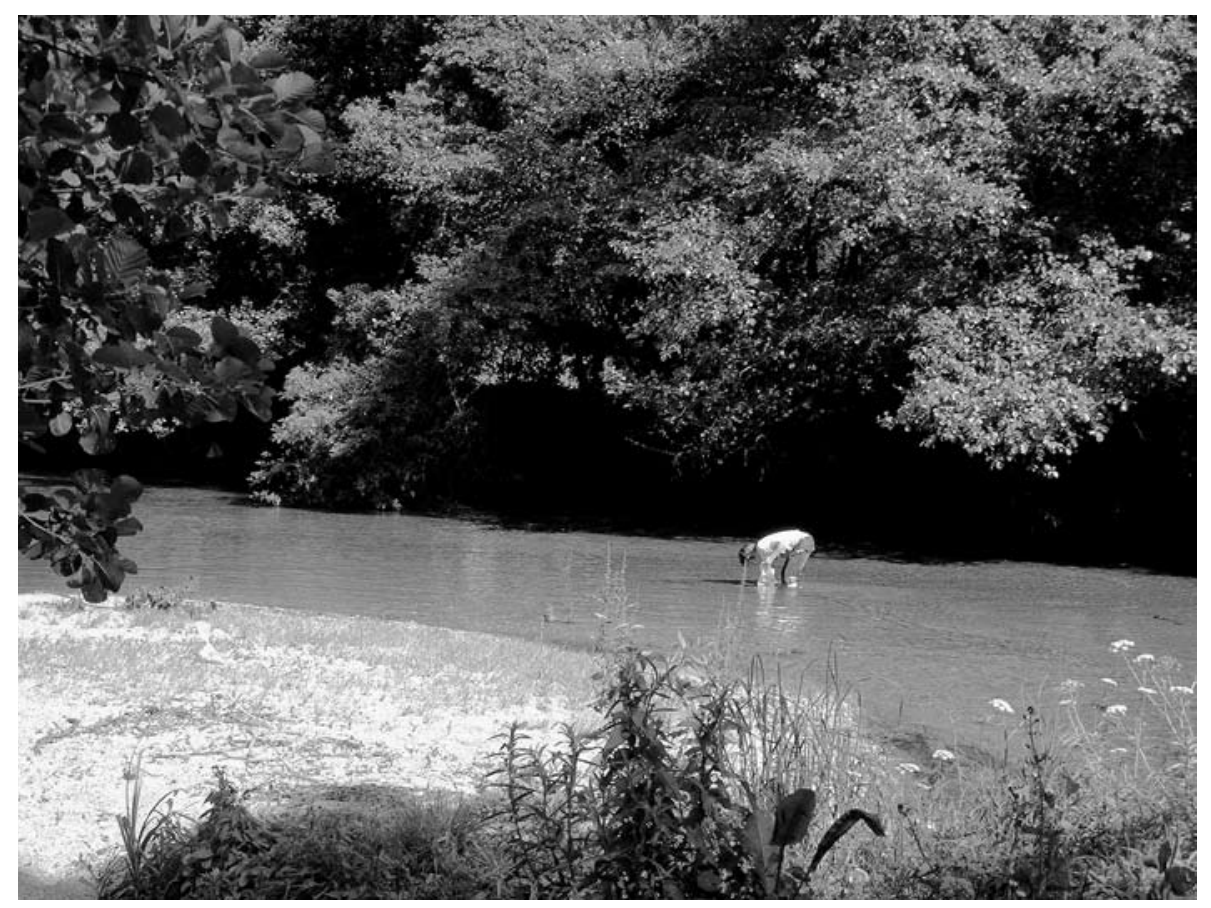

Fig. 15. O rio Neiva em Tregosa. Parte da barra lateral, arenosa, utilizada como praia fluvial. Vista para montante.

Fig. 15. The Neiva River in Tregosa. Channel and lateral sand bar. View to upstream. 


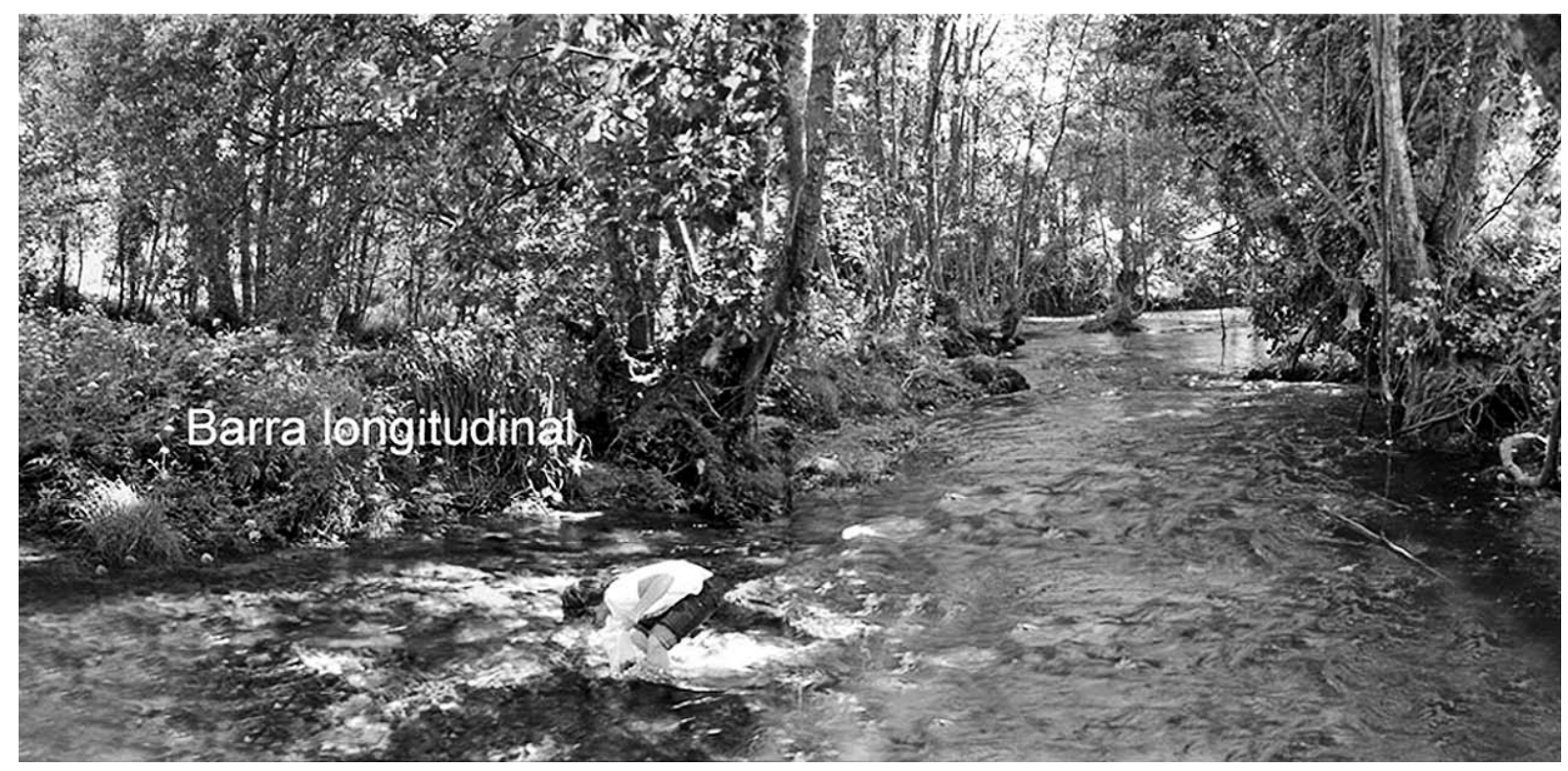

Fig. 16. Barra longitudinal de cascalho no rio Neiva em Tregosa. O canal principal, com leito de cascalho (local da colheita), contorna do lado direito a barra. Vista para jusante.

Fig. 16. Longitudinal bar of gravel in the Neiva River in Tregosa, The main channel, with gravel bed (place of sampling), surrounds the right side of the bar. View to downstream.

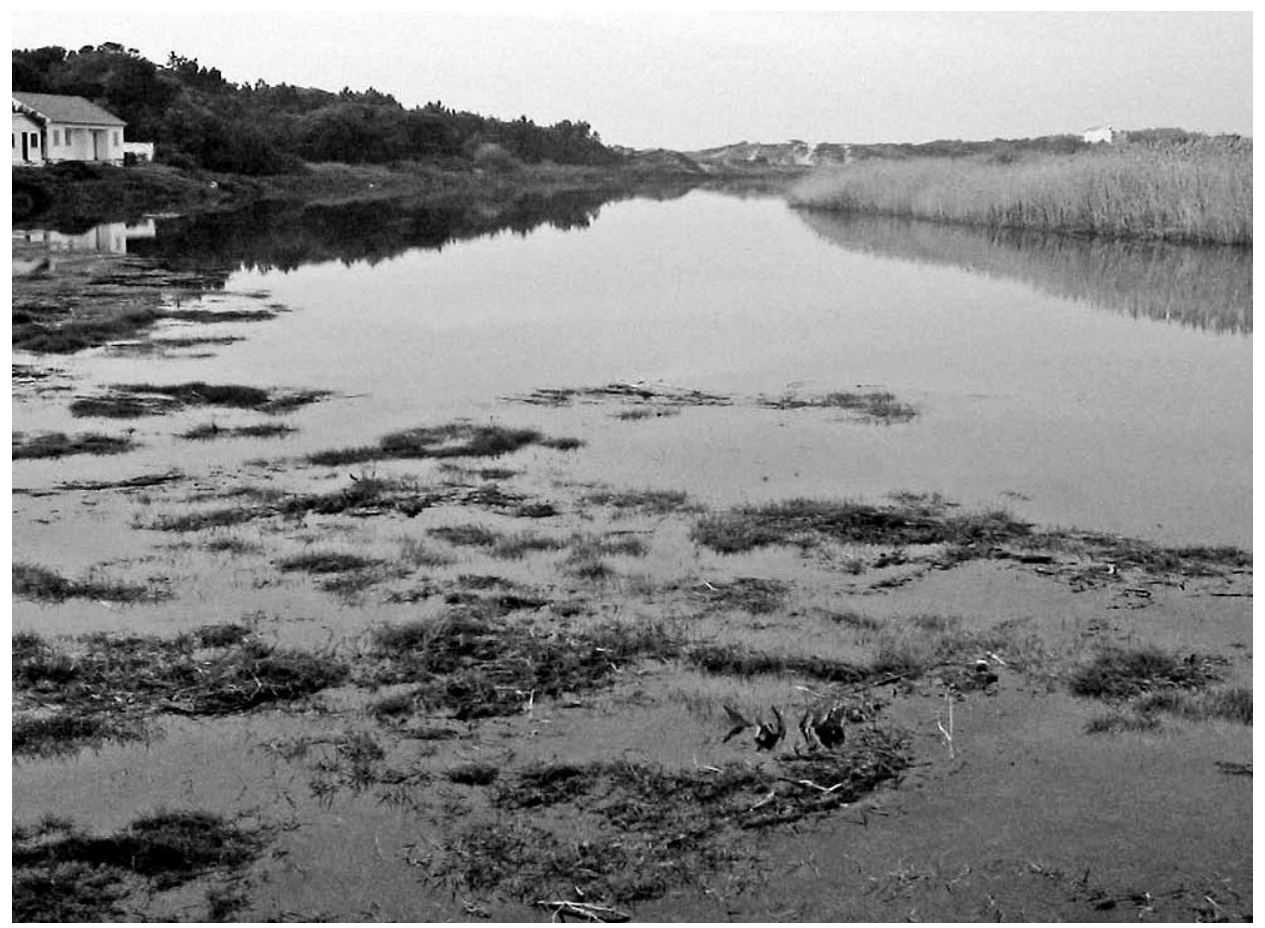

Fig. 17. O rio Neiva, perto da sua foz em Castelo do Neiva.

Fig. 17. The Neiva River, near its mouth in Castelo do Neiva. 


\section{Tipos de Canais no Rio neiva e Seus Controlos}

A ação dos fluxos aquosos manifesta-se por erosão, transporte e sedimentação, sendo a velocidade da corrente fluvial dependente do declive e da forma do canal. A relação entre a velocidade e a taxa de erosão / transporte da corrente é diretamente proporcional. No entanto, nas correntes naturais, a velocidade varia dentro dos canais onde circulam e, com ela, a capacidade e a competência daquelas. As zonas de menor velocidade no canal fluvial são junto das margens e do leito, devido ao atrito da água com estas superfícies. Num canal sinuoso ou simplesmente com curvaturas esporádicas, a zona de maior velocidade de fluxo é deslocada pela força centrífuga para a margem côncava.

Ao longo do perfil longitudinal o rio Neiva apresenta diversos tipos de canal. Na área de cabeceira os controlos dominantes na ação da corrente são o declive do canal e a litologia onde este é modelado. $\mathrm{O}$ primeiro faz aumentar a velocidade da corrente, mas, como nestas zonas, embora íngremes, o fluxo aquoso circula essencialmente no substrato granítico não alterado, a ação erosiva é retardada. Neste setor da bacia do rio Neiva o trajeto das correntes aproveita as zonas de fratura e de rocha mais meteorizada.

Outros controlos na velocidade das correntes fluviais são a relação entre a largura e a profundidade da secção do canal e do caudal de descarga. No que se refere à largura do canal e para o mesmo declive do talvegue, podemos dizer que, de uma maneira geral, quando aumenta a largura do canal a velocidade da corrente tende a diminuir, devido ao aumento do espaço disponível para se movimentar. No rio Neiva verifica-se esta relação. A velocidade das águas é notavelmente mais lenta nas zonas onde a largura do canal é superior. A descarga é o volume de água que atravessa a secção do canal por unidade de tempo (SCHUMm 2005). A velocidade da corrente varia ao longo do rio, dependendo da área da secção do canal e do declive deste. Desta maneira, a dinâmica fluvial responde às variações do caudal mas não de igual modo à escala espacial da bacia nem ao mesmo tempo. $\mathrm{O}$ efeito sobre a energia da corrente depende das caraterísticas hidrológicas da bacia, nomeadamente do afluxo de água ao canal pelos afluentes, número de afluentes, contributo de descarga de cada um deles, sua localização na bacia e posição relativamente ao canal coletor, entre outras. No caso do rio Neiva os afluentes distribuem-se ao longo da bacia (Fig. 3), sendo o caudal do rio acrescentado em vários pontos do seu trajeto, aumentando em direção à foz. A área de bacia de cada um dos afluentes é variável. As maiores são as dos ribeiros de Nevoinho e de Pombarinhos, que confluem num só, desaguando no rio Neiva perto de Balugães. Na bacia do Neiva este é um local importante de acréscimo da descarga fluvial.

A sinuosidade, representa a geometria em planta da forma do canal. É um parâmetro usado vulgarmente para descrever o grau de atividade dum canal com meandros. O parâmetro sinuosidade define-se como a razão do comprimento do canal pelo comprimento do vale. Assim, um canal perfeitamente reto terá uma sinuosidade de 1,0 enquanto um canal com uma sinuosidade de 3,0 ou mais será claramente meandriforme.

O vale do rio Neiva, a partir de Duas Igrejas até Arcozelo, é um vale aberto e de fundo largo. O rio tem um traçado irregular com troços mais retilíneos (Fig. 3), fazendo cotovelos bem marcados. Estas mudanças do traçado fluvial são paralelas e, por vezes, seguem as direções de falha cartografadas na bacia (Fig. 9), sendo o efeito da instalação do canal segundo a direção das estruturas geológicas, presentes no substrato granítico e metassedimentar. Entre Arcozelo e Vilar das Almas o canal é meandriforme, mas o vale tem um traçado geral retilíneo. Este troço é o que apresenta meandros mais livres, vagueando o rio nas aluviões por entre os campos da planície de inundação.

Os troços demasiadamente retos em rios aluviais são muito raros na natureza, embora um segmento do rio possa manter um alinhamento próximo do retilíneo por um longo período de tempo. No rio Neiva há alguns segmentos retilíneos, no entanto, em comprimento cada um é inferior a $1 \mathrm{~km}$. Entre Arcozelo e Vilar das Almas o contorno retilíneo do vale está relacionado com uma falha, segundo a qual em etapas mais antigas o vale foi modelado. Atualmente o canal corre nas suas aluviões (Figs. 3 e 13) e mostra meandros não condicionados por qualquer estrutura geológica. A partir de Vilar das Almas a sinuosidade é mais concordante com a orientação das fraturas. A seguir, próximo de Balugães o traçado mostra novamente sinuosidade muito semelhante à do tipo existente entre Arcozelo e Vilar das Almas. É possível observar com clareza os meandros, identificando na margem mais ativa a erosão provocada pelo movimento do fluxo aquoso e, na oposta, a barra de meandro resultante da acumulação de sedimentos arenosos. Neste rio, há alguns locais, descritos anteriormente, onde a corrente se bifurca, acumulando os sedimentos em barras no meio do canal com crescimento de tendência longitudinal.

A dimensão dos sedimentos presentes no leito dos canais é entendida como uma indicação da dinâmica das correntes. Além da população dominante depositada, existe frequentemente uma fração subor- 
dinada com dimensão distinta daquela. Os canais com leito de cascalho, de seixos pequenos e grandes, contêm algum areão e areia numa percentagem cujos valores são normalmente inferiores a $10 \%$. Nos rios de áreas montanhosas os canais podem ainda apresentar blocos. A presença de partículas de tamanhos tão diversos no leito do canal causa interações complexas entre elas, durante os processos de erosão, transporte e deposição.

Os canais com leito de cascalho diferem dos canais com leito arenoso e com leito de blocos, não apenas pelo tamanho das suas partículas, mas, também, pela morfologia do canal e pela topografia da área onde se inserem. Os que apresentam leito arenoso, geralmente têm baixo gradiente e localizam-se em vales amplos e em grandes áreas aplanadas. A maior parte dos rios com leito de blocos, possuem canais muito inclinados e encontram-se em áreas íngremes de montanha. Contudo, há exceções para ambos. Os canais com leito de cascalho são frequentes em vales de montanha com declive moderado. A distinção entre estes tipos de canais está incluída na classificação fluvial proposta por Rosgen (1994, 1996).

O rio Neiva apresenta claramente caraterísticas que se inserem em vários tipos. $\mathrm{O}$ mais frequente é o canal ter leito de cascalho (seixos pequenos e grandes). Nalgumas zonas podem encontrar-se, no leito, partículas de maior e de menor dimensão, populações de sedimentos de dimensão bloco e outra de areias, respetivamente em zonas próximas da nascente e a partir de Vilar das Almas e em zonas com declive menos acentuado. Os blocos que aparecem no leito do rio, são, na maioria, da litologia local existente nas vertentes do vale, deslocados por ação da gravidade. Na parte mais a montante, mais próximo da área de cabeceira da bacia, observa-se que os blocos no canal possuem sempre alguma matriz com dimensão de seixo e areão. Verifica-se que a percentagem da fração de dimensão areia tende a aumentar para jusante.

\section{Classificação do Rio neiva Quanto ao Tipo de Canal}

As classificações dos canais fluviais são uma ferramenta de estudo. Da variedade de classificações disponíveis, existem dois sistemas de classificações que foram usadas neste trabalho, a classificação de Montgomery \& Buffington (1997) e a classificação de Rosgen (1994, 1996).

O sistema de classificação proposto por Montgomery \& Buffington (1997) foi desenvolvido e usado para descrever os rios instalados em montanhas de vertentes íngremes e com foz a uma curta distância da costa do Pacífico. Neles, os referidos autores identificaram a seguinte sequência de formas: na cabeceira da bacia hidrográfica, colinas com vertentes íngremes e vales com fundo e vertentes muito inclinadas; vales suaves na zona intermédia da bacia e vales com baixo gradiente na parte final. Os sistemas fluviais estudados apresentavam desde canais de montanha com leito rochoso aos canais aluviais, cuja carga sedimentar era principalmente constituída por areia, limo e argila. Este sistema de classificação confronta a diversidade e a relação entre rios/relevo/canais, diferenciando tipos de canais organizados por ordem decrescente do gradiente do rio (Fig. 18). A classificação contempla o início do sistema fluvial, o topo do relevo divisório da drenagem (hillslope), tendo sido inventariadas em direção a jusante as concavidades, em substrato rochoso (hollow) e em coluvião (colluvial), as rampas, e os canais do tipo aluvial. Além das formas, foram identificados os processos dominantes, os quais estão intimamente relacionados com o declive do setor, refletindo-se nas caraterísticas dos sedimentos, isto é, na respetiva dimensão e forma. Na cabeceira, próximo da divisória, predominam a difusão e os processos coluvionares enquanto os canais aluviais têm génese por processos fluviais. Os sedimentos em associação com o declive condicionam o tipo de canal, a distribuição das áreas de deposição/erosão e o espaçamento destas. No domínio dos processos fluviais foram definidos cinco tipos morfológicos de canais: cascade, step-pool, plane-bed, pool-riffle e dune-ripple (Fig. 19).

Aplicando a classificação de Montgomery \& Buffington (1997), encontram-se no rio Neiva canais do tipo A, B, C, D e E (Fig. 20 e Quadro 1).

Nos pântanos do Oural os processos ativos estão dependentes da dinâmica da água nas vertentes, ou seja, do escoamento difuso e concentrado. $\mathrm{O}$ domínio dos processos fluviais tem início quando o escoamento canalizado começa, verificando-se este ainda no setor das cabeceiras, próximo do limite de bacia dependendo de cada afluente. O canal do tipo A (cascade) encontra-se na área próxima da nascente, onde o fluxo é canalizado e corre num canal único mas íngreme e também na zona das Azenhas do Neiva, em regime de fluxo baixo. Em Porrinhoso o canal foi classificado como sendo do tipo A/B (cascade e step-pool), já que apresenta caraterísticas variáveis entre estes dois tipos. Em Godinhaços e Panque, o canal é do tipo B (step-pool). Este é reconhecido em troços onde ocorre mudança brusca na inclinação do canal, aparecendo degraus no leito. Forma-se uma sucessão de degraus e piscinas, nos quais a velocidade da água varia, sendo o fluxo muito rápido e mais lento, respetivamente. Em Duas 


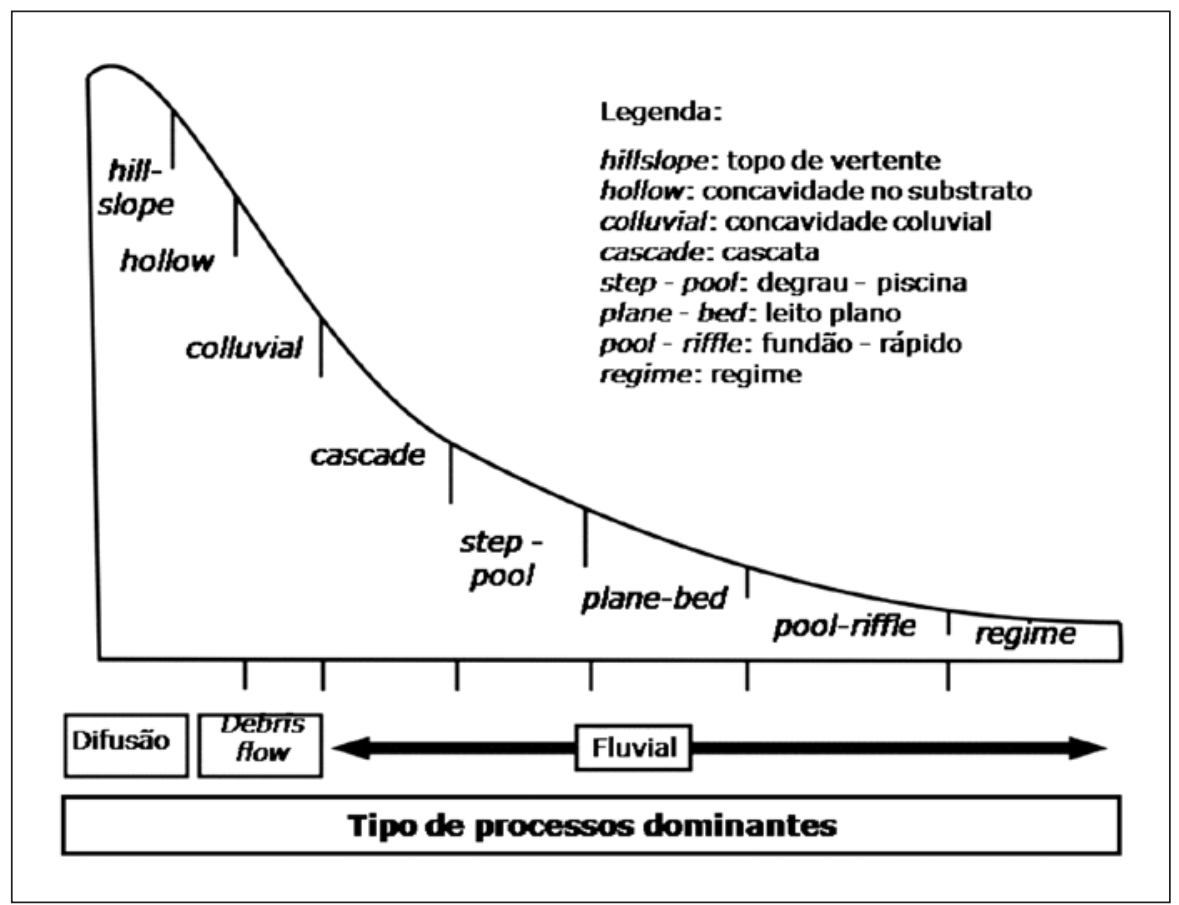

Fig. 18. Perfil longitudinal esquemático, desde o topo da vertente até aos canais aluviais, mostrando a distribuição geral dos tipos de canais e dos processos nas bacias de drenagem de montanha. Figura adaptada de Montgomery \& Buffington (1997).

Fig. 18. Longitudinal profile, showing the general distribution of the channels types and processes in mountain drainage basins. Figure adapted from Montgomery \& Buffington (1997).

Igrejas o canal é do tipo C (plane-bed), apresentando um leito relativamente plano, deslocando-se o fluxo aquoso com pouca turbulência. Nas localidades de Arcozelo, Vilar das Almas e Tregosa, o canal é classificado como sendo do tipo D (pool-riffle). Em determinadas zonas, o rio apresenta barras laterais, por vezes barras de meandro, e barras centrais, não atingindo a caraterística de um escoamento de tipo entrançado. Em Cossourado foi atribuída a classificação do tipo $\mathrm{C} / \mathrm{D}$. Localmente o canal é do tipo $\mathrm{C}$, mas o declive é mais baixo, frequente nos canais do tipo D. Na zona de Balugães verifica-se o oposto. O canal foi classificado como sendo do tipo $\mathrm{D} / \mathrm{C}$, isto é, localmente de tipo $\mathrm{D}$, no entanto, tem um declive mais frequente do tipo C. Na zona da foz, o leito arenoso apresenta megaripples e ripples, habituais em canais do tipo E (dune-ripple). No entanto, o declive é frequente nos canais do tipo $\mathrm{D}$ e as formas não atingem claramente dunas, pelo que foi classificado como D/E (Fig. 20 e Quadro 1).

Rosgen (1994, 1996) utiliza um código alfanumérico para classificar os canais, baseando-se em cinco parâmetros morfométricos do canal fluvial e da superfície de cheia: a taxa de entrincheiramento; razão largura/profundidade; sinuosidade; declive do leito e o tamanho médio das partículas na superfície do leito. Estes cinco parâmetros são usados para distinguir sete principais tipos de canais identificados por letras de "A" a "G" e cada tipo de canal principal tem um número designado que reflete o tamanho das partículas do leito. Os canais com leito de blocos, seixos grandes e pequenos apresentam os números "2", " 3 " e "4", respetivamente, e são os únicos a que se aplicam estes critérios. As letras minúsculas "a", "b" e "c", especificam gradientes de canais fora do intervalo típico para um determinado tipo de corrente (Fig. 21).

A aplicação da classificação de Rosgen (1994, 1996) ao rio Neiva (Quadro 1) revelou que o tipo de canal identificado para a zona da nascente (tipo A) e para as localidades de Porrinhoso e Godinhaços $\left(\mathrm{A} / \mathrm{Aa}^{+}\right)$exibem alguma concordância com as observações efectuadas no campo e com os resultados obtidos segundo a classificação de Montgomery \& Buffington. Nos outros setores, os valores de entrincheiramento não são consistentes com os restantes critérios. Foi possível obter combinações entre a sinuosidade, largura/profundidade e declive, exceto para os troços observados em Duas Igrejas, Tregosa e Castelo de Neiva, troços assinalados com os números "4", "10" e "11" respetivamente (Fig. 20). O grau de entrincheiramento não apresenta qualquer semelhança com os tipos de canal sugeridos nas combinações obtidas entre os restantes critérios. 


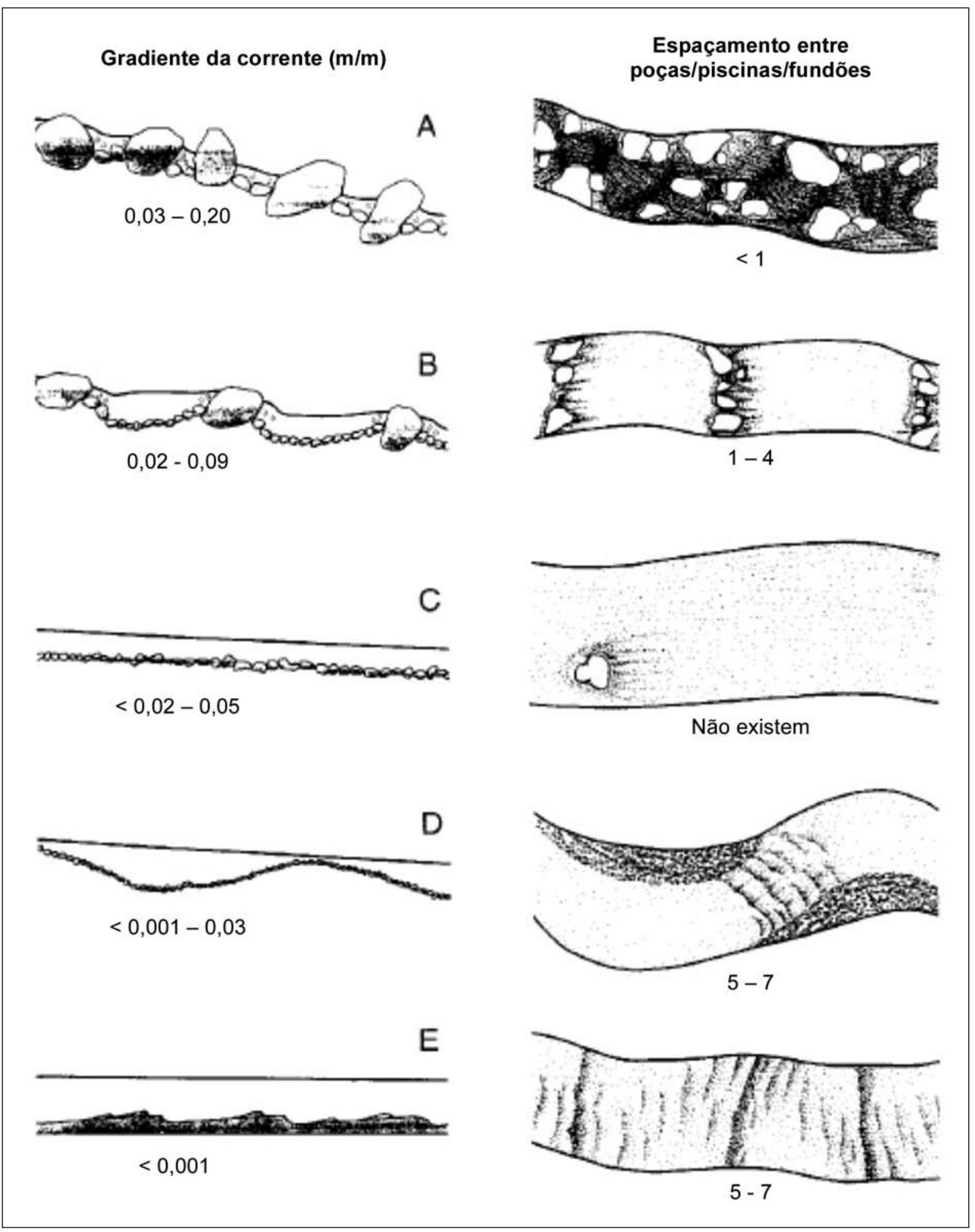

Fig. 19. Morfologia em secção longitudinal e correspondente vista em planta de cada tidpo de canal em regime de fluxo baixo: A - cascade; B - step-pool; C - plane-bed; D - pool-riffle; E - dune-ripple. Adaptado de Montgomery \& Buffington (1997).

Fig. 19. Morphology in longitudinal section and plan view corresponding to each type of channel under low flow: A - cascade; B - step-pool; C - plane-bed; D - pool-riffle; E - dune-ripple. Adapted from Montgomery \& Buffington (1997). 


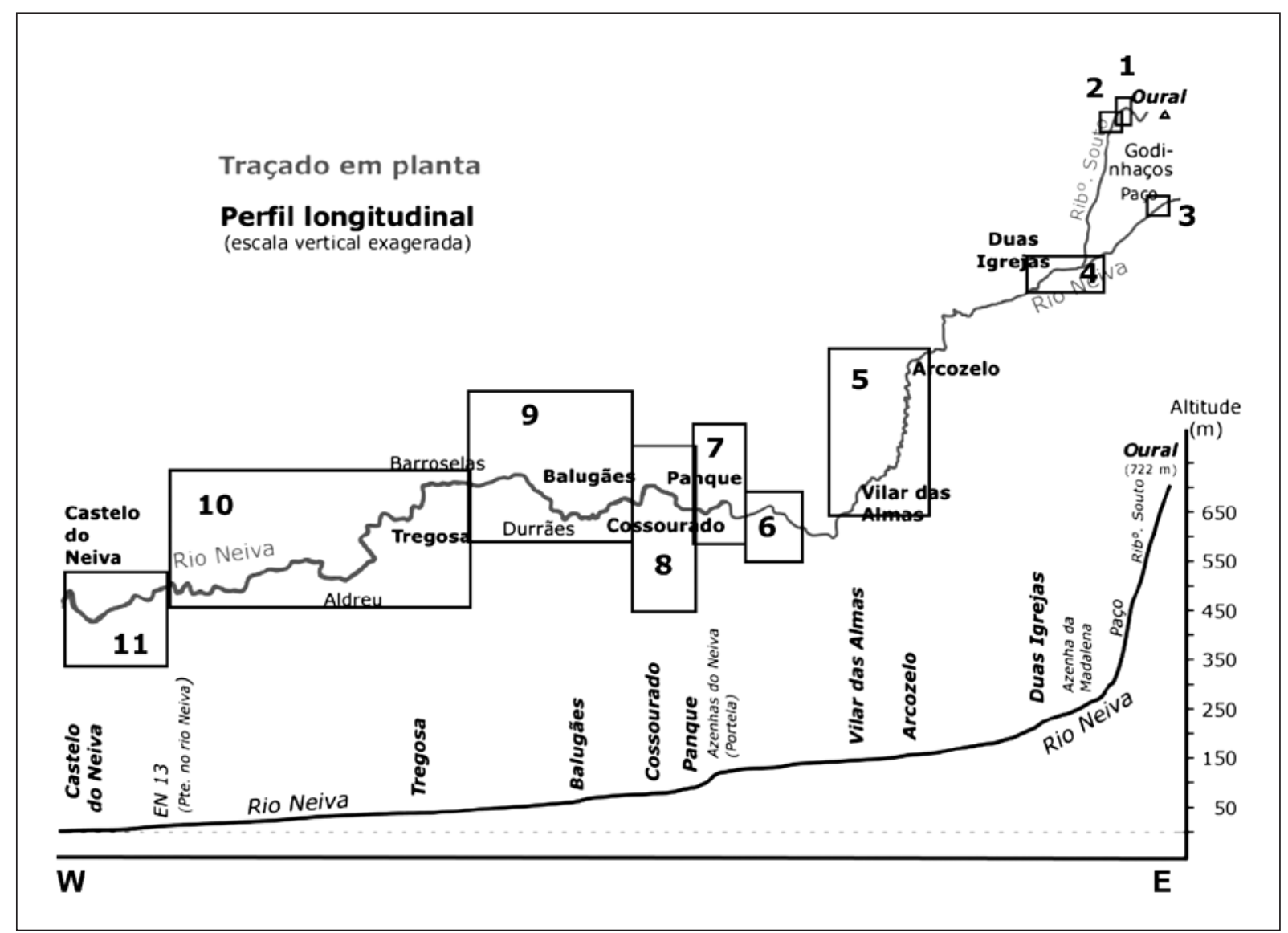

Fig. 20. Localização e designação numérica dos setores onde foram aplicados os critérios morfométricos, referidos no texto e no Quadro 1. A distância aproximada Oural - Castelo do Neiva é de $40 \mathrm{~km}$. Escala vertical exagerada 1700 vezes.

Fig. 20. Sectors location and numerical designation, where morphometric criteria were applied. References are in accordance with the explanations in the text and Table 1. The approximate distance Oural - Castelo do Neiva is $40 \mathrm{~km}$. Vertical scale exaggerated 1700 times. 
Quadro 1. Tipos de canais no rio Neiva, aplicando as classificações de Montgomery \& Buffington (1997) e Rosgen (1994, 1996). Características morfológicas dos principais tipos de canais segundo a classificação de Rosgen.

Table 1. Types of channels in the Neiva River, applying the classifications of Montgomery \& Buffington (1997) and Rosgen (1994, 1996). Morphological characteristics of the main types of channels according to the Rosgen classification.

\begin{tabular}{|c|c|c|c|c|c|c|c|c|c|}
\hline \multirow{2}{*}{ N..$^{\circ}$ do troço no perfil } & \multicolumn{3}{|c|}{ Tipos de canal } & \multirow[b]{2}{*}{$\begin{array}{l}\text { Entrinchei- } \\
\text { ramento }\end{array}$} & \multirow{2}{*}{\multicolumn{2}{|c|}{ Sinuosidade }} & \multirow{2}{*}{\multicolumn{2}{|c|}{$\begin{array}{c}\text { Largura/ } \\
\text { Profundidade }\end{array}$}} & \multirow[b]{2}{*}{ Declive } \\
\hline & \multicolumn{2}{|c|}{$\begin{array}{c}\text { Montgomery- } \\
\text { Buffington }\end{array}$} & Rosgen & & & & & & \\
\hline $\begin{array}{l}1 \\
\text { Porrinhoso }\end{array}$ & \multicolumn{2}{|r|}{$\mathbf{A}$} & $A$ & 1,5 & \multicolumn{2}{|c|}{1,022} & \multicolumn{2}{|l|}{1,71} & 0,070 \\
\hline $\begin{array}{l}2 \\
\text { Porrinhoso } \\
\end{array}$ & \multicolumn{2}{|c|}{$\mathbf{A} / \mathbf{B}$} & $\begin{array}{c}A \\
A a+\end{array}$ & 1,2 & \multicolumn{2}{|c|}{1,029} & \multicolumn{2}{|l|}{0,5} & 0,104 \\
\hline $\begin{array}{l}3 \\
\text { Godinhaços }\end{array}$ & \multicolumn{2}{|r|}{ B } & $A / A a^{+}$ & 1,07 & \multicolumn{2}{|c|}{1,027} & \multicolumn{2}{|l|}{3} & 0,046 \\
\hline $\begin{array}{l}4 \\
\text { Duas Igrejas }\end{array}$ & \multicolumn{2}{|r|}{$\mathrm{C}$} & - & Sem limite & \multicolumn{2}{|c|}{1,129} & \multicolumn{2}{|l|}{1,1} & 0,014 \\
\hline $\begin{array}{l}\mathbf{5} \\
\text { Arcozelo } \\
\text { Vilar das Almas }\end{array}$ & \multicolumn{2}{|r|}{ D } & ${ }^{*} \mathrm{DA}$ & $\begin{array}{l}1,27 \\
0,20\end{array}$ & \multicolumn{2}{|c|}{1,559} & \multicolumn{2}{|l|}{$\begin{array}{l}4 \\
5\end{array}$} & 0,002 \\
\hline $\begin{array}{l}6 \\
\text { Azenhas do Neiva }\end{array}$ & \multicolumn{2}{|r|}{$\mathbf{A}$} & $* A a+$ & 1,50 & \multicolumn{2}{|c|}{0,966} & \multicolumn{2}{|l|}{4,3} & 0,233 \\
\hline $\begin{array}{l}7 \\
\text { Panque }\end{array}$ & \multicolumn{2}{|r|}{ B } & $* A$ & 2,00 & \multicolumn{2}{|c|}{1,190} & \multicolumn{2}{|l|}{6,7} & 0,053 \\
\hline $\begin{array}{l}8 \\
\text { Cossourado }\end{array}$ & & C/D & $* A$ & 1,35 & & & 7,7 & & 0,032 \\
\hline $\begin{array}{l}9 \\
\text { Balugães }\end{array}$ & & $/ \mathrm{C}$ & ${ }^{*} A$ & 3,30 & & & 8,3 & & 0,054 \\
\hline $\begin{array}{l}\mathbf{1 0} \\
\text { Tregosa }\end{array}$ & & D & - & 1,53 & & & 4,3 & & 0,031 \\
\hline $\begin{array}{l}11 \\
\text { Cast. Neiva }\end{array}$ & & $/ \mathbf{E}$ & - & 2 & & & 15 & & 0,015 \\
\hline & & itérios da & assificaç & proposta $p$ & r Rosg & $(1994,19$ & 96) & & \\
\hline Tipo de canal & $\mathrm{Aa}+$ & A & B & $\mathrm{C}$ & $\mathrm{D}$ & DA & E & $\mathrm{F}$ & G \\
\hline Entrincheiramento & $<1,4$ & $<1,4$ & $1,4-2,2$ & $>2,2$ & $\mathrm{~N} / \mathrm{A}$ & $>2,2$ & $>2,2$ & $<1,4$ & $<1,4$ \\
\hline Sinuosidade & $<1,1$ & $<1,2$ & $>1,2$ & $>1,4$ & $<1,1$ & $1,1-1,6$ & $>1,6$ & $>1,4$ & $>1,2$ \\
\hline $\begin{array}{l}\text { Largura/ } \\
\text { Profundidade }\end{array}$ & $<12$ & $<12$ & $>12$ & $>12$ & $>40$ & $<40$ & $<12$ & $<12$ & $<12$ \\
\hline Declive & $>0,10$ & $\begin{array}{c}0,04 \\
\mathrm{a} \\
0,099\end{array}$ & $\begin{array}{c}0,02 \\
\mathrm{a} \\
0,039\end{array}$ & $<0,02$ & $<0,04$ & $<0,005$ & $<0,02$ & $<0,02$ & $\begin{array}{c}0,02 \\
\mathrm{a} \\
0,039\end{array}$ \\
\hline
\end{tabular}

Entrincheiramento (Largura do canal no plano traçado a 2 vezes a profundidade do canal de cheia, a dividir pela largura do canal em situação de cheia). Sinuosidade (Comprimento do rio / Comprimento do vale). Largura/Profundidade (do canal de cheia). Declive (do canal, em \%).

Tipo de Canal | Características morfológicas dos principais tipos de canais propostas por Rosgen

A Degrau-piscina (step-pool) e cascata: piscinas de cascata e de erosão, energia elevada, baixo armazenamento de sedimentos, estável.

B | Rápidos (riffles \& rapids): alguns poços/piscinas de erosão, barras raras, estável.

C | Sequências fundão-rápido (pool-riffle): meandriforme, barras de meandro, planície de inundação bem desenvolvida, margens estáveis ou instáveis.

D | Entrançado: múltiplos canais, barras móveis, erosão, deposição, grande fornecimento de sedimentos, margens erodíveis.

DA | Anastomosado: canais múltiplos, fundões-rápidos, planície de inundação com vegetação, zonas húmidas adjacentes, margens estáveis.

E Meandros livres: planície de inundação bem desenvolvida, fundões-rápidos, transporte de sedimentos relativamente alta.

F | Meandros incisos: meandros talhados nos vales, planície de inundação pobre, fundão-rápido, margens estáveis ou instáveis.

G | Ravinas: talhados em vertentes e veigas, grande fornecimento de sedimentos, margens instáveis, step-pool. 

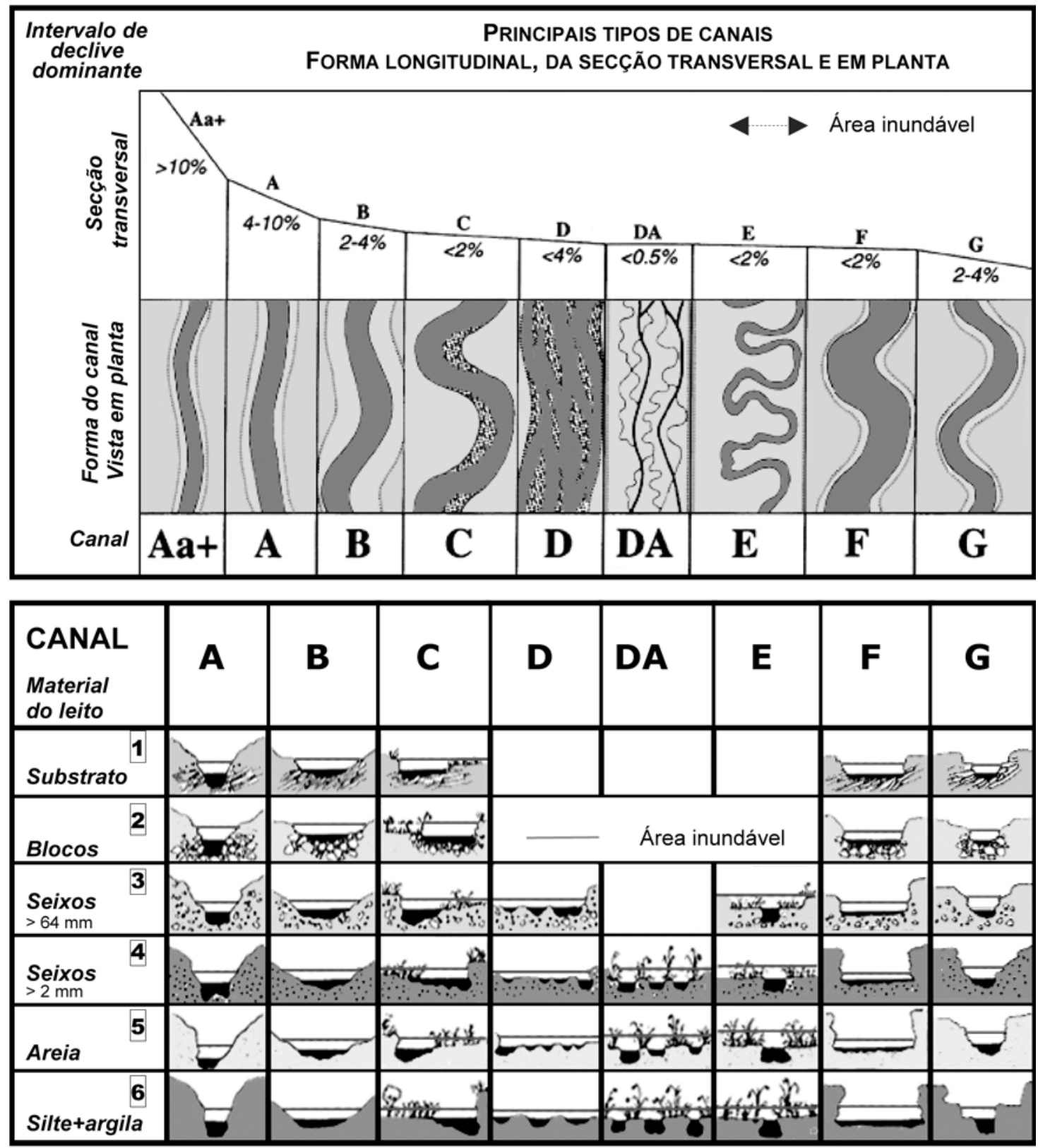

\begin{tabular}{|l|c|c|c|c|c|c|c|c|}
\hline $\begin{array}{l}\text { Entrinchei- } \\
\text { ramento }\end{array}$ & $<1,4$ & $1,4-2,2$ & $>2,2$ & $\mathrm{~N} / \mathrm{A}$ & $>2,2$ & $>2,2$ & $<1,4$ & $<1,4$ \\
\hline Sinuosidade & $<1,2$ & $>1,2$ & $>1,4$ & $<1,1$ & $1,1-1,6$ & $>1,6$ & $>1,4$ & $>1,2$ \\
\hline $\begin{array}{l}\text { Largural } \\
\text { Profundidade }\end{array}$ & $<12$ & $>12$ & $>12$ & $>40$ & $<40$ & $<12$ & $<12$ & $<12$ \\
\hline Declive & $\begin{array}{c}0,04 \\
\mathrm{a} \\
0,099\end{array}$ & $\begin{array}{c}0,02 \\
\mathrm{a} \\
0,039\end{array}$ & $<0,02$ & $<0,04$ & $<0,005$ & $<0,02$ & $<0,02$ & $\begin{array}{c}0,02 \\
\mathrm{a} \\
0,039\end{array}$ \\
\hline
\end{tabular}

Fig. 21. Classificação baseada em critérios morfométricos. Estão esboçados quarenta e um tipos de canais função da secção longitudinal e transversal dos canais, a vista em planta do traçado dos canais e a relação com os materiais do leito. Adaptado de Rosgen (1994, 1996).

Fig. 21. Classification based on morphometric criteria. Are outlined forty-one types of channels according to the longitudinal section and transverse channels, with the channel morphology in plan view, and the relationship with the sediments of the channel bed. Adapted from Rosgen $(1994,1996)$. 


\section{CONCLuSÕES}

A aplicação do sistema de classificação proposto por Montgomery \& Buffington, revelou que existem no rio Neiva canais do tipo A, B, C, D e E. Relativamente à aplicação da classificação de Rosgen à tipologia dos canais do rio Neiva, conclui-se que apenas nas zonas da nascente, Porrinhoso e Godinhaços, existe alguma coerência com os estudos de campo e com os resultados obtidos com a classificação de Montgomery \& Buffington. Nos outros setores, os valores de entrincheiramento não são consistentes com os restantes critérios. Conclui-se que a classificação de Rosgen não é aplicável ao rio Neiva.

A diversidade morfológica observada no rio Neiva tem valor importante para suporte da biodiversidade, já que, a estrutura dos habitats está intimamente dependente da morfologia e caraterísticas do local, no que diz respeito, por exemplo, à natureza do substrato - rochoso e aluvião.

No rio Neiva existem ao longo do seu troço, vários tipos de canal, verificando-se a repetição de alguns tipos a partir de Panque, o que coincide com uma rotura de declive bem visível no perfil longitudinal.

Este tipo de estudos permitem compreender a dinâmica do canal à escala espaço-tempo e interpretar os indicadores de estabilidade/instabilidade do canal, de evolução, num curto espaço de tempo. Trata-se de uma abordagem integrada do sistema fluvial a qual é um bom suporte para o ordenamento territorial das áreas ribeirinhas, especialmente quando aplicado à gestão ambiental destas.

Nota: Texto escrito segundo o novo acordo ortográfico.

\section{AGRADECIMENTOS}

O trabalho foi desenvolvido no âmbito das linhas de investigação do Centro de Ciências da Terra (CCT/UM) e do Centro de Geologia da Universidade do Porto (CGUP/ /UM), unidade de investigação inserida no Programa de Financiamento Plurianual da FCT, cofinanciada pelo Governo Português e pela União Europeia (FEDER).

\section{BIBLIOGRAFIA}

Alves, A.M.C. 1996. Causas e Processos da Dinâmica Sedimentar na Evolução Actual do Litoral do Alto Minho. Braga: Universidade do Minho. Tese de Doutor em Ciências (Geologia), 442 p.

Alves, M.I.C. 1995. Materiais Plio-quaternários do Alto Minho. Produtos de Meteorização e Depósitos Fluviais na Bacia do rio Lima e região de Alvarães. Braga: Universidade do Minho. Tese de Doutor em Ciências (Geologia), 277 p.

Alves, M.I.C. 1999. Definição formal da Formação de Alvarães (Placenciano da região do Minho - NW Portugal). Comun. Inst. Geol. e Mineiro 86: 197-212.

Alves, M.I.C \& Oliveira, V. 2008. A composição das aluviões do rio Neiva. Indicadores do passado. In: P.M. CALlaPEZ; R.B. Rocha; J.L. MARQUes; L.S. CUnHA \& P.M. Dinis (eds.) A Terra. Conflitos e Ordem: Homenagem ao Professor Ferreira Soares. Coimbra: Museu Min. Geol. Univ. Coimbra: 129-135.

Dingman, S.L. 2009. Fluvial Hydraulics. New York: Oxford University Press, $576 \mathrm{p}$.

Instituto do Ambiente. 2003. Atlas do Ambiente Digital. Continente, 1/1.000.000: Informação Vectorial, tema altimetria. Lisboa. Instituto do Ambiente.

Montgomery, D.R. \& Buffington, J.M. 1997. Channel-reach morphology in mountain drainage basins. Geol. Soc. Am. Bull. 109: 596-611.

OliveIRA, V.R.G. 2007. O ambiente fluvial. Perspectiva geomorfológica e sedimentológica. Exemplos na bacia do rio Neiva. Braga. Universidade do Minho. Dissertação de Mestrado em Ciências do Ambiente, Ramo Qualidade Ambiental, 191 p.

Pereira, E. (Coordenador) 1989. Carta geológica de Portugal, escala 1/200 000, Folha 1. Lisboa. Serviços Geológicos de Portugal.

PEREIRA, E. (Coordenador) 1992. Carta geológica de Portugal, escala 1/200 000. Notícia Explicativa da Folha 1. Lisboa. Serviços Geológicos de Portugal.

Press, F. \& Siever, R. 2001. Understanding Earth. New York: W.H. Freeman, $121 \mathrm{p}$.

RosGen, D. 1994. A classification of natural rivers. Catena 22: 169-199.

RosGen, D. 1996. Applied river morphology. Wildland Hydrology. Colorado: Pragosa Springs, 290 p.

Schumm, S.A. 1977. The fluvial system. New York: Wiley, $338 \mathrm{p}$.

Schumm, S.A. 2005. River variability and complexity. Cambridge: Cambridge University Press, 220 p. 